\title{
Cochrane
}

Library

Cochrane Database of Systematic Reviews

\section{Rubber dam isolation for restorative treatment in dental patients} (Review)

Wang Y, Li C, Yuan H, Wong MCM, Zou J, Shi Z, Zhou X

Wang Y, Li C, Yuan H, Wong MCM, Zou J, Shi Z, Zhou X.

Rubber dam isolation for restorative treatment in dental patients.

Cochrane Database of Systematic Reviews 2016, Issue 9. Art. No.: CD009858.

DOI: 10.1002/14651858.CD009858.pub2.

www.cochranelibrary.com 
TABLE OF CONTENTS

HEADER 1

ABSTRACT

PLAIN LANGUAGE SUMMARY

SUMMARY OF FINDINGS

BACKGROUND

OBJECTIVES

METHODS

RESULTS

Figure 1.

Figure 2.

Figure 3.

DISCUSSION

AUTHORS' CONCLUSIONS

ACKNOWLEDGEMENTS

REFERENCES

CHARACTERISTICS OF STUDIES

DATA AND ANALYSES

Analysis 1.1. Comparison 1 Rubber dam versus cotton rolls, Outcome 1 Survival rate (6 months).

Analysis 1.2. Comparison 1 Rubber dam versus cotton rolls, Outcome 2 Survival rate (24 months). 
[Intervention Review]

\section{Rubber dam isolation for restorative treatment in dental patients}

Yan Wang ${ }^{1}$, Chunjie $\mathrm{Li}^{2}$, He Yuan ${ }^{3}$, May CM Wong${ }^{4}$, Jing Zou ${ }^{1}$, Zongdao Shi ${ }^{5}$, Xuedong Zhou ${ }^{3}$

1Department of Pediatric Dentistry, West China Hospital of Stomatology, Sichuan University, State Key Laboratory of Oral Diseases, Chengdu, China. 2Department of Head and Neck Oncology, West China Hospital of Stomatology, Sichuan University, State Key Laboratory of Oral Diseases, Chengdu, China. ${ }^{3}$ Department of Operative Dentistry and Endodontics, West China Hospital of Stomatology, Sichuan University, State Key Laboratory of Oral Diseases, Chengdu, China. ${ }^{4}$ Dental Public Health, Faculty of Dentistry, The University of Hong Kong, Hong Kong, China. ${ }^{5}$ Department of Oral and Maxillofacial Surgery, West China Hospital of Stomatology, Sichuan University, State Key Laboratory of Oral Diseases, Chengdu, China

Contact address: Xuedong Zhou, Department of Operative Dentistry and Endodontics, West China Hospital of Stomatology, Sichuan University, State Key Laboratory of Oral Diseases, No. 14, 3rd Section, Ren Min South Road, Chengdu, Sichuan, 610041, China. zhouxd_scu@outlook.com.

Editorial group: Cochrane Oral Health Group.

Publication status and date: New, published in Issue 9, 2016.

Citation: Wang Y, Li C, Yuan H, Wong MCM, Zou J, Shi Z, Zhou X. Rubber dam isolation for restorative treatment in dental patients. Cochrane Database of Systematic Reviews 2016, Issue 9. Art. No.: CD009858. DOI: 10.1002/14651858.CD009858.pub2.

Copyright @ 2016 The Cochrane Collaboration. Published by John Wiley \& Sons, Ltd.

\section{A B S T R A C T}

\section{Background}

Successful restorations in dental patients depend largely on the effective control of moisture and microbes during the procedure. The rubber dam technique has been one of the most widely used isolation methods in dental restorative treatments. The evidence on the effects of rubber dam usage on the longevity of dental restorations is conflicting. Therefore, it is important to summarise the available evidence to determine the effects of this method.

\section{Objectives}

To assess the effects of rubber dam isolation compared with other types of isolation used for direct and indirect restorative treatments in dental patients.

\section{Search methods}

We searched the following electronic databases: Cochrane Oral Health's Trials Register (searched 17 August 2016), Cochrane Central Register of Controlled Trials (CENTRAL; 2016, Issue 7) in the Cochrane Library (searched 17 August 2016), MEDLINE Ovid (1946 to 17 August 2016), Embase Ovid (1980 to 17 August 2016), LILACS BIREME Virtual Health Library (Latin American and Caribbean Health Science Information database; 1982 to 17 August 2016), SciELO BIREME Virtual Health Library (1998 to 17 August 2016), Chinese BioMedical Literature Database (CBM, in Chinese) (1978 to 30 August 2016), VIP (in Chinese) (1989 to 30 August 2016), and China National Knowledge Infrastructure (CNKI, in Chinese) (1994 to 30 August 2016). We searched ClinicalTrials.gov and the World Health Organization International Clinical Trials Registry Platform, OpenGrey and Sciencepaper Online (in Chinese) for ongoing trials. There were no restrictions on the language or date of publication when searching the electronic databases.

\section{Selection criteria}

We included randomised controlled trials (including split-mouth trials) assessing the effects of rubber dam isolation for restorative treatments in dental patients.

\section{Data collection and analysis}

Two review authors independently screened the results of the electronic searches, extracted data and assessed the risk of bias of the included studies. We resolved disagreement by discussion. 


\section{Main results}

We included four studies that analysed 1270 participants (among which 233 participants were lost to follow-up). All the included studies were at high risk of bias. We excluded one trial from the analysis due to inconsistencies in the presented data.

The results indicated that dental restorations had a significantly higher survival rate in the rubber dam isolation group compared to the cotton roll isolation group at six months in participants receiving composite restorative treatment of non-carious cervical lesions (risk ratio (RR) 1.19, 95\% confidence interval (CI) 1.04 to 1.37, very low-quality evidence). It also showed that the rubber dam group had a lower risk of failure at two years in children undergoing proximal atraumatic restorative treatment in primary molars (hazard ratio ( $\mathrm{HR}) 0.80,95 \% \mathrm{Cl} 0.66$ to 0.97 , very low-quality evidence). One trial reported limited data showing that rubber dam usage during fissure sealing might shorten the treatment time. None of the included studies mentioned adverse effects or reported the direct cost of the treatment, or the level of patient acceptance/satisfaction. There was also no evidence evaluating the effects of rubber dam usage on the quality of the restorations.

\section{Authors' conclusions}

We found some very low-quality evidence, from single studies, suggesting that rubber dam usage in dental direct restorative treatments may lead to a lower failure rate of the restorations, compared with the failure rate for cotton roll usage. Further high quality research evaluating the effects of rubber dam usage on different types of restorative treatments is required.

\section{PLAIN LANGUAGE SUMMARY}

\section{Does isolating the site of a dental restoration during treatment improve the performance of the restoration?}

\section{Review question}

This review examined whether different isolation methods affect the performance of dental restorations.

\section{Background}

Restorative dental treatments are used to repair damage to teeth caused by tooth decay or accidents. Creating a physical barrier around a treatment site to reduce contamination of the site with saliva is a common practice. Reducing the amount of saliva in the area may enable the materials used for repair to bond together more effectively, improving the performance and reliability of the restoration. It may also reduce exposure to bacteria in the mouth.

Two methods of creating a barrier are commonly used; either a rubber dam around the tooth or cotton rolls together with suction to remove excess saliva. The rubber dam method involves using a sheet of latex in a frame. A small hole is made in the sheet and it is placed over the tooth to be treated creating a barrier around it. Using a rubber dam can isolate the tooth from the rest of the person's mouth, which allows the tooth to be repaired dry and with relatively less exposure to bacteria in the mouth. A common alternative method of isolation of the tooth is the use of cotton rolls combined with the removal of excess saliva by suction. The evidence on the effects of rubber dam usage versus cotton roll usage is conflicting.

\section{Study characteristics}

The evidence in this review, which was carried out together with Cochrane Oral Health, is up-to-date as of 17 August 2016 . We included four studies that evaluated 1037 participants, mostly children, who were undergoing different types of dental restorative treatments, using materials which require effective moisture control to reduce failure rates. For example, fissure sealing, resin or composite fillings at the gum margin, and proximal atraumatic restorative treatment in primary molars. All of the included studies compared the use of rubber dam and cotton rolls as two different isolation methods.

\section{Key results}

There is some evidence to suggest that the use of a rubber dam may increase the survival time of dental restorations compared to the use of cotton rolls as an isolation method.

The studies did not include possible side effects.

\section{Quality of the evidence}

The evidence presented is of very low quality due to the small amount of available studies, uncertain results and problems related to the way in which the available studies were conducted. 
SUMMARY OF FINDINGS

\section{Summary of findings for the main comparison. Rubber dam versus cotton rolls for restorative treatment in dental patients}

Rubber dam versus cotton rolls for restorative treatment in dental patients

Patient or population: dental patients

Settings: China and Kenya

Intervention: rubber dam versus cotton rolls

\begin{tabular}{|c|c|c|c|c|c|c|}
\hline \multirow[t]{3}{*}{ Outcomes } & \multicolumn{2}{|c|}{$\begin{array}{l}\text { Illustrative comparative } \\
\text { risks }{ }^{\star}(95 \% \mathrm{Cl})\end{array}$} & \multirow{3}{*}{$\begin{array}{l}\text { Relative ef- } \\
\text { fect } \\
(95 \% \mathrm{Cl})\end{array}$} & \multirow{3}{*}{$\begin{array}{l}\text { No of partici- } \\
\text { pants } \\
\text { (studies) }\end{array}$} & \multirow{3}{*}{$\begin{array}{l}\text { Quality of the } \\
\text { evidence } \\
\text { (GRADE) }\end{array}$} & \multirow[t]{3}{*}{ Comments } \\
\hline & Assumed risk & $\begin{array}{l}\text { Correspond- } \\
\text { ing risk }\end{array}$ & & & & \\
\hline & Cotton rolls & Rubber dam & & & & \\
\hline $\begin{array}{l}\text { Survival rate (6 } \\
\text { months) } \\
\text { assessed clinical- } \\
\text { ly and radiographi- } \\
\text { cally } \\
\text { Follow-up: mean } 6 \\
\text { months }\end{array}$ & 765 per 1000 & $\begin{array}{l}\mathbf{9 1 0} \text { per } \mathbf{1 0 0 0} \\
\text { (796 to } 1000)\end{array}$ & $\begin{array}{l}\text { RR } 1.19 \\
\text { (1.04 to } 1.37)\end{array}$ & $\begin{array}{l}162 \\
\text { (1 study) }\end{array}$ & $\begin{array}{l}\oplus \ominus \ominus \ominus \\
\text { very low } 1\end{array}$ & $\begin{array}{l}\text { There was weak evidence showing that the use of rubber dam } \\
\text { might result in higher survival rate of the restorations com- } \\
\text { pared to cotton rolls at } 6 \text { months' follow-up } \\
\text { Weak evidence also indicating the usage of rubber dam might } \\
\text { relatively increase the survival rate of restorations after } 24 \\
\text { months' follow-up compared to cotton rolls (HR } 0.80,95 \% \mathrm{Cl} \\
0.66 \text { to } 0.97 ; 559 \text { participants; } 1 \text { study; very low-quality evi- } \\
\text { dence) }\end{array}$ \\
\hline
\end{tabular}

*The basis for the assumed risk (e.g. the median control group risk across studies) is provided in footnotes. The corresponding risk (and its $95 \%$ confidence interval) is based on the assumed risk in the comparison group and the relative effect of the intervention (and its $95 \% \mathrm{Cl}$ )

Cl: confidence interval; HR: hazard ratio; RR: risk ratio

GRADE Working Group grades of evidence

High quality: Further research is very unlikely to change our confidence in the estimate of effect.

Moderate quality: Further research is likely to have an important impact on our confidence in the estimate of effect and may change the estimate.

Low quality: Further research is very likely to have an important impact on our confidence in the estimate of effect and is likely to change the estimate.

Very low quality: We are very uncertain about the estimate.

1 Downgraded 3 times due to being a single study, at high risk of bias and for indirectness: the included study had high risk of bias and was only conducted in China or Kenya population that may not be applicable in other populations. 


\section{B A C K G R O U N D}

\section{Description of the condition}

Restorative dental treatments are used to repair damage to teeth caused by caries or trauma. Direct restorative dental treatments (commonly known as 'fillings') repair damage to the visible tooth, such as restorations using either amalgam or a resin composite material. Indirect restorations are prepared outside the person's mouth, using a dental impression from the prepared tooth. Examples of indirect restorations include inlays, onlays, crowns, bridges and veneers.

Successful restorations depend on a number of factors, but perhaps the most important ones are moisture and microbe control. Excluding moisture and saliva from the tooth or root being restored facilitates the bonding of the restorative material to the tooth and decreases the risk of infection or re-infection. Poor bonding or secondary caries may compromise the success or longevity of the restoration, or both.

\section{Description of the intervention}

A common method of isolation and moisture control in restorative dentistry is the use of cotton rolls combined with aspiration by saliva ejector. This technique is widely available and low cost, but has the disadvantage that the dentist is required to replace sodden cotton rolls frequently during the treatment to keep the operative field dry.

An alternative method of isolation of the tooth undergoing restorative treatment is a rubber dam, an isolation method, introduced to the dental profession by Dr Sanford C Barnum on 15 March 1864 (Elderton 1971a; Elderton 1971b; Elderton 1971c). Since then, many researchers have improved its application and it is now a frequently used, practical alternative to cotton balls (Bhuva 2008; Carrotte 2000; Carrotte 2004; Reuter 1983). A rubber dam is usually a small sheet of latex (though non-latex versions are available) placed in a frame. A small hole is made in the sheet and placed over the tooth to be treated. The rubber dam is held on to the tooth being restored by means of a small clamp. This isolates the tooth from the rest of the person's mouth, which keeps the tooth to be restored dry and relatively less exposed to intraoral bacteria.

Potential advantages of the use of a rubber dam include superior isolation of the tooth to be treated from the saliva in the mouth (Cochran 1989), providing the dentist with improved visibility, reduced mirror fogging, enhanced visual contrast, soft tissue retraction (Reid 1991), protection of the person by preventing ingestion or aspiration of instruments (Susini 2007; Tiwana 2004), materials, or irrigant (Cohen 1987), and preventing oral soft tissues from contact with irritating or harmful materials used during operative procedures, such as phosphoric acids or sodium hypochlorite (Lynch 2003). There is also a reduction in the risk of cross-infection in the dental practice by decreasing the microbial content of splatters and air turbine aerosols produced during dental treatment (Harrel 2004).

However, there are real and perceived negative effects to the use of rubber dams. Most often cited are concerns over patient acceptance, time needed for application, cost of materials and equipment, insufficient training and inconvenience (Hill 2008; Koshy 2002; Stewardson 2002). Latex allergy, rubber dam clamp fracture (Sutton 1996), and damage to the mucosa when placing or removing the rubber dam, in rare cases, may also impede the wide use of rubber dam.

A number of modifications of rubber dam techniques have been described. John Mamoun suggested the use of a rubber dam with a custom prosthesis to achieve dry-field isolation of the distal molars with short clinical crowns (Mamoun 2002). Also, the slit rubber dam technique used when preparing teeth for indirect restoration could promote operating efficiency (Perrine 2005). Further developments in rubber dam technique are ongoing.

\section{How the intervention might work}

Creating a physical barrier around a treatment site to reduce contamination due to moisture and microbes is common practice in medical and dental procedures. Isolating the tooth to be restored from the contamination of moisture or saliva in restoration placement may promote the bonding of the restorative materials to the tooth, while rubber dam usage is mandatory for endodontics for reasons of safety and cross infection control. The use of a rubber dam in restorative dentistry has the added advantage of providing the dentist with a broader work surface which also traps small pieces of debris and treatment solutions protecting the person from inadvertently swallowing these. When rubber dams are used in association with amalgam restorations, they may reduce the person's exposure to potentially harmful adverse effects of mercury ingestion (Halbach 2008; Kremers 1999).

\section{Why it is important to do this review}

Both rubber dam and cotton rolls are currently used in dentistry to isolate the treatment field and to exclude moisture. There are advantages and disadvantages associated with each method from the different points of view of person and dentist. Moreover, several randomised controlled trials have been conducted to determine whether the use of a rubber dam for restorative treatments influences the treatment outcomes (Carvalho 2010; Kemoli 2010; Ma 2012). However, the results from these trials appear to be conflicting. The purpose of this systematic review is to evaluate the effectiveness of the rubber dam as an isolation and moisture reduction technique used in restorative dentistry, together with any adverse or negative effects. This information will then be available so that both dentists and their patients can make informed decisions about the benefits and possible negative effects of different isolation and moisture control techniques to be used for specific dental restorations.

\section{O B J E C T IVES}

To assess the effects of rubber dam isolation compared with other types of isolation used for direct and indirect restorative treatments in dental patients.

\section{METHODS}

\section{Criteria for considering studies for this review Types of studies}

All randomised controlled trials or quasi-randomised controlled trials (including split-mouth/cross-over studies). 


\section{Types of participants}

People undergoing any type of direct or indirect restorative treatment. There were no restrictions of age or gender.

Restorative treatment included direct anterior restorations, direct posterior restorations, inlays, onlays, veneers, crowns, etc.

\section{Types of interventions}

The intervention group received a rubber dam for isolation and moisture control, either alone or combined with other active treatment (such as saliva aspiration). The comparison (control) group received an alternative method of isolation and moisture control (such as cotton rolls) with or without the same active treatment as in the intervention group.

\section{Types of outcome measures}

\section{Primary outcomes}

- Survival rate of the restorations at 6 months, 1, 2, 5 and 10 years after restorative treatments. Survival means the restorations were still correctly present or having only a slight wear or defect at the margin less than $0.5 \mathrm{~mm}$ in depth when assessed. If the restorations were either completely lost, or were fractured with defects $0.5 \mathrm{~mm}$ in depth or greater, had secondary caries or inflammation of the pulp, any of these situations was labelled as treatment failure.

- Adverse events. Any reported adverse events related to any of the active interventions during the treatment phase. These included events affecting the operator or the patient (e.g. damage to skin or mucosa, allergic reactions to latex).

\section{Secondary outcomes}

- Clinical evaluation of restoration's quality, including colour match, cavo-surface marginal discolouration, anatomic form, marginal adaptation and caries, which were assessed at baseline (i.e. within one month following the placement) as well as 6 months, 1, 2, 5 and 10 years of subsequent recalls. The evaluation should be based upon the US Public Health Service (USPHS) criteria and its evolution (Hickel 2007), which had specific clinical criteria followed for the assessment of each category.

- Costs: the direct cost of the treatment, the time needed to accomplish the treatment.

- Participant acceptance/satisfaction. Participants expressed satisfaction with the procedure using any validated instrument.

\section{Search methods for identification of studies}

For the identification of studies included or considered for this review, we developed detailed search strategies for each database searched. We based these on the search strategy developed for MEDLINE but revised appropriately for each database to take account of differences in controlled vocabulary and syntax rules. There were no language restrictions in the searches. We translated papers when necessary.

\section{Electronic searches}

The search included the following databases:

- Cochrane Oral Health's Trials Register (searched 17 August 2016) (Appendix 1);
- Cochrane Central Register of Controlled Trials (CENTRAL; 2016, Issue 7) in the Cochrane Library (searched 17 August 2016) (Appendix 2);

- MEDLINE Ovid (1946 to 17 August 2016) (Appendix 3);

- Embase Ovid (1980 to 17 August 2016) (Appendix 4);

- LILACS BIREME Virtual Health Library (Latin American and Caribbean Health Science Information database; 1982 to 17 August 2016) (Appendix 5);

- SciELO BIREME Virtual Health Library (Scientific Electronic Library Online; 1998 to 17 August 2016) (Appendix 6);

- Chinese BioMedical Literature Database (CBM, in Chinese) (1978 to 30 August 2016) (Appendix 7);

- VIP (in Chinese, 1989 to 30 August 2016) (Appendix 8);

- China National Knowledge Infrastructure (CNKI, in Chinese) (1994 to 30 August 2016) (Appendix 9).

\section{Searching other resources}

\section{Searching for unpublished studies and ongoing studies}

We searched the following sources for unpublished and ongoing studies:

- US National Institutes of Health Ongoing Trials Register ClinicalTrials.gov (clinicaltrials.gov/; searched 17 August 2016) (Appendix 10);

- World Health Organization International Clinical Trials Registry Platform (apps.who.int/trialsearch; searched 17 August 2016) (Appendix 10);

- OpenGrey (1980 to 17 August 2016) (Appendix 11);

- Sciencepaper Online (in Chinese, to 30 August 2016) (Appendix 12).

\section{Handsearching}

We handsearched the following journals:

- Oral Surgery, Oral Medicine, Oral Pathology, Oral Radiology and Endodontology (1995 to October 2015);

- Journal of Endodontics (1975 to October 2015);

- International Endodontic Journal (1967 to October 2015);

- Caries Research (1967 to October 2015);

- Journal of Dental Research (1970 to October 2015);

- International Journal of Oral Science (2009 to October 2015);

- Dental Traumatology (1985 to October 2015);

- Australian Endodontic Journal (1967 to October 2015).

In addition, we explored the following Chinese dental journals:

- Chinese Journal of Stomatology (2005 to October 2015);

- West China Journal of Stomatology (2005 to October 2015);

- Journal of International Stomatology (2005 to October 2015);

- Journal of Clinical Stomatology (2005 to October 2015);

- Journal of Practical Stomatology (2005 to October 2015);

- Journal of Comprehensive Stomatology (2005 to October 2015);

- Journal of Modern Stomatology (2005 to October 2015);

- Chinese Journal of Conservative Dentistry (2005 to October 2015);

- Chinese Journal of Dental Prevention and Treatment (2005 to October 2015). 


\section{Reference lists and contacts}

We screened the references of the included articles for studies. We contacted authors and experts in the field to identify unpublished randomised controlled trials.

\section{Data collection and analysis}

Two review authors (Yan Wang (YW), He Yuan (HY)) independently selected studies, extracted and managed data, and assessed risk of bias. We resolved any differences of opinion by discussion.

\section{Selection of studies}

We used a two-step process to identify studies to be included in this review. We screened titles and abstracts from the electronic searches to identify studies which may have met the inclusion criteria for this review. We obtained full-text copies of all apparently eligible studies and two review authors evaluated these further in detail to identify those studies which actually met all the inclusion criteria. We recorded those studies which did not meet the inclusion criteria in the excluded studies section of the review and noted the reason for exclusion in the Characteristics of excluded studies table.

\section{Data extraction and management}

We designed and piloted a data extraction form on two included studies. The data extraction form included the following information.

- Article title, publication time, journal, reviewer ID.

- Inclusion re-evaluation.

- Types of studies: methods of randomisation, methods of allocation concealment, methods of blinding, location of the study, number of centres, time frame, source of funding.

- Types of participants: source of participants, types of disease, diagnostic criteria, age, sex, eligibility criteria, numbers of participants randomised to each group, number evaluated in each group.

- Types of intervention and comparison: details of the treatments received in the intervention and comparison groups, together with the type of restoration procedure and any co-interventions used.

- Types of outcome measures: outcome, time point that the outcome was recorded, exact statistics.

\section{Assessment of risk of bias in included studies}

The review authors assessed the risk of bias for each included study in each of seven domains using the 'Risk of bias' tool as described in Chapter 8 of the Cochrane Handbook for Systematic Reviews of Interventions (Higgins 2011). For each domain, we presented explanations and judged them as low risk, unclear risk and high risk. The domains and explanations were as follows.

- Random sequence generation (selection bias): selection bias (biased allocation to interventions) due to inadequate generation of a randomised sequence.

- Allocation concealment (selection bias): selection bias (biased allocation to interventions) due to inadequate concealment of the allocation sequence from those involved in the enrolment and assignment of participants.
- Blinding of participants and personnel (performance bias): performance bias due to knowledge of the allocated interventions by participants and personnel during the study.

- Blinding of outcome assessment (detection bias): detection bias due to knowledge of the allocated interventions by outcome assessors.

- Incomplete outcome data (attrition bias): attrition bias due to amount, nature or handling of incomplete outcome data.

- Selective reporting (reporting bias): reporting bias due to selective outcome reporting.

- Other bias: bias due to problems not covered elsewhere in the table.

We categorised the overall risk of bias according to Additional Table 1 and summarised the 'Risk of bias' graphically.

\section{Measures of treatment effect}

For the primary outcome of survival/success rate of the restorative treatment, we expressed the measure of the treatment effect as a hazard ratio (HR) or risk ratio (RR) with $95 \%$ confidence interval (Cl). If the studies did not quote HRs, we calculated the log HRs and the standard errors (SE) from the available summary statistics or Kaplan-Meier curves according to the methods proposed by Parmar and colleagues (Parmar 1998), or requested the data from study authors. For the primary outcome of incidence of adverse events, we used the RR and $95 \% \mathrm{Cls}$ to estimate the treatment effect.

For the secondary outcomes, we used RR and $95 \% \mathrm{Cls}$ for dichotomous data and mean difference (MD) and 95\% Cls for continuous data.

\section{Unit of analysis issues}

The unit of analysis was the participant.

\section{Cross-over/split-mouth trials}

We assessed carry-over or carry-across effect of designs if we considered them a problem. For an ideal study (which reported MD and standard deviation (SD) of both groups and the MD together with SD/SE between the two groups), we calculated the intracluster correlation coefficient (ICC); if more than one ideal study existed, we calculated a mean ICC. We used this ICC in the calculation of MD and $\mathrm{SD} / \mathrm{SE}$ of the other similar cross-over/split-mouth studies. If there was no ideal study, we assumed the ICC was 0.5 (Higgins 2011).

\section{Trials with multiple intervention arms}

For randomised controlled trials with multiple treatment arms, there were two steps to deal with this problem. First, we tried to combine treatment arms, or we analysed the most relevant treatment and controls groups. For such trials, we collected the data in all the groups and recorded details in the Characteristics of included studies table.

\section{Dealing with missing data}

Where information about trial procedures was incomplete or unclear in a trial report, or data were missing or incomplete, the review authors attempted to contact the trial authors to obtain clarification. Where we could not obtain missing data, we did not include the trial in the meta-analysis but described the results narratively. Where SDs were missing from continuous outcome data, we attempted to calculate these based on other available 
data (e.g. Cls, SEs, t values, $\mathrm{P}$ values, $\mathrm{F}$ values), as discussed in the Cochrane Handbook for Systematic Reviews of Interventions (Higgins 2011).

\section{Assessment of heterogeneity}

We considered two types of heterogeneity.

\section{Clinical heterogeneity}

We judged clinical heterogeneity from the similarity between the types of participants, interventions and outcome measures in each trial.

\section{Statistical heterogeneity}

We calculated statistical heterogeneity through the $\mathrm{Chi}^{2}$ test and measured the effect using the $I^{2}$ statistic or $P$ value $(P$ value $<0.1$ indicated statistically significant heterogeneity). The classification of statistical heterogeneity was as follows.

- $0 \%$ to $40 \%$ implied slight heterogeneity.

- $30 \%$ to $60 \%$ moderate heterogeneity.

- $50 \%$ to $90 \%$ substantial heterogeneity.

- $75 \%$ to $100 \%$ considerable heterogeneity.

\section{Assessment of reporting biases}

We planned to report bias using a funnel plot if the number of included studies had exceeded 10 . The asymmetry of the funnel plot would indicate a possibility of reporting bias. Further detection would use Begg's test (Begg 1994) for dichotomous data and Egger's test (Egger 1997) for continuous data.

\section{Data synthesis}

We planned to perform meta-analyses only when there were little clinical heterogeneity and statistical heterogeneity $(12$ less than $75 \%$ ). If the number of studies in one outcome did not exceed four we planned to use the fixed-effect model; otherwise, we planned to use the random-effects model.

\section{Subgroup analysis and investigation of heterogeneity}

If the number of studies in one outcome exceeded 10, we planned to use meta-regression to detect clinical heterogeneity (using STATA 11.0). If there was clinical heterogeneity, we planned to perform subgroup analysis of the following:

- types of restorative treatments;

- age of the participants;

- location of the restoration (anterior/posterior teeth);
- types of adhesives.

Due to the small number of eligible studies and a lack of suitable data from the included studies, we were unable to do subgroup analyses; however, we will consider carrying this out if more eligible studies are included in future updates of this review.

\section{Sensitivity analysis}

We planned to perform a sensitivity analysis to detect the stability of the outcomes. If there had been a sufficient number of included trials, we would have based sensitivity analysis on risk of bias (low risk of bias versus high or unclear risk of bias).

\section{Presentation of main results}

We developed a 'Summary of findings' table for the reported primary outcomes of this review using GRADEproGDT software (GRADEproGDT). We assessed the quality of the body of evidence with reference to the overall risk of bias of the included studies, the directness of the evidence, the inconsistency of the results, the precision of the estimates, the risk of publication bias, the magnitude of the effect and whether there was evidence of a dose response. GRADE categorises the quality of the body of evidence for each of the primary outcomes as high, moderate, low or very low (Atkins 2004; Guyatt 2008; Higgins 2011).

\section{RES U LT S}

\section{Description of studies}

See Characteristics of included studies and Characteristics of excluded studies tables.

\section{Results of the search}

The electronic searches retrieved 1213 references, which reduced to 781 after de-duplication. Handsearching of the journals did not identify any additional studies. After reviewing the titles and abstracts, we disregarded 762 references that did not match our criteria and were clearly ineligible. We obtained the full-text copies of the remaining 19 studies for further evaluation. We classified one study into 'studies awaiting classification' as we were waiting responses from the authors on the details of the method of randomisation used, preformation of allocation concealment and the funding sources (Alhareky 2014). We excluded nine studies (13 references). Finally, four studies (five references), including one Chinese study and three English studies, were eligible for inclusion (Ammann 2013; Carvalho 2010; Kemoli 2010; Ma 2012).

We have presented this process as a flow chart in Figure 1. 
Figure 1. Study flow diagram.

\section{3 records identified} through database searching
0 additional records identified through other sources

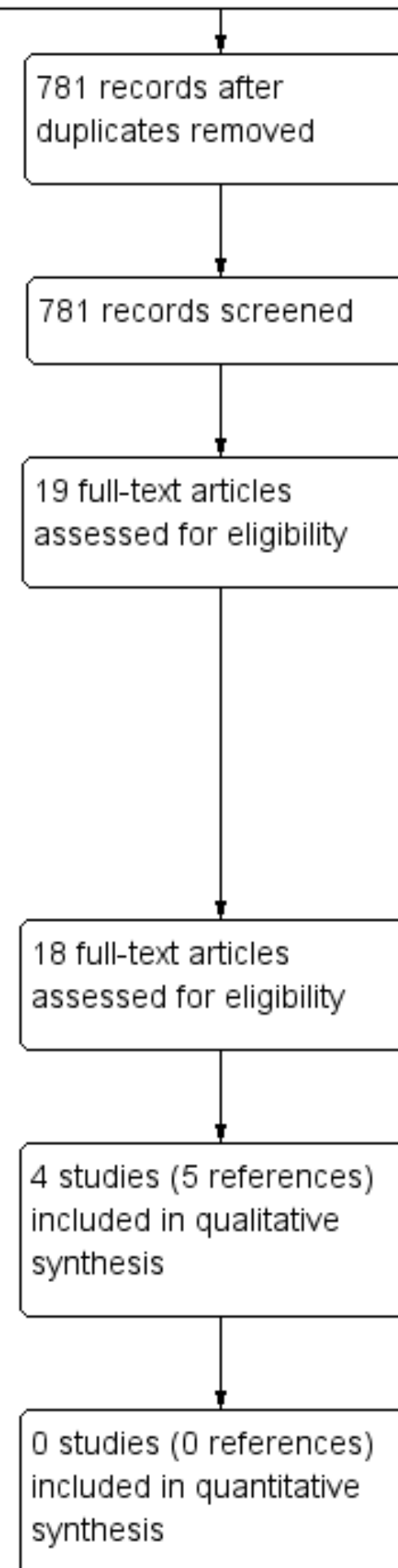

762 records excluded

1 full-text article awaiting classification

13 full-text articles (9 studies) excluded for the following reasons:

- controlled clinical trial (CCT) (6 studies)

- inappropriate study design (1 study)

- inappropriate statistical analysis (2 studies) 


\section{Included studies}

This review included four randomised controlled trials (RCTs), which were published between 2010 and 2013 (Ammann 2013; Carvalho 2010; Kemoli 2010; Ma 2012). See Characteristics of included studies table for details of the included studies.

\section{Characteristics of the trial designs and settings}

All of the included studies used a parallel design (Ammann 2013; Carvalho 2010; Kemoli 2010; Ma 2012). The studies were conducted in Germany (Ammann 2013), Brazil (Carvalho 2010), Kenya (Kemoli 2010) and China (Ma 2012). One study was carried out in a private dental clinic setting (Ammann 2013), one in a dental hospital setting (Ma 2012), and two in a school setting (Carvalho 2010; Kemoli 2010). One study performed a sample size calculation; however, the study did not mention the method used (Kemoli 2010). The other three studies did not mention sample size calculations (Ammann 2013; Carvalho 2010; Ma 2012). Two studies did not state their funding sources (Ma 2012), and one study stated that they received both industry and non-industry funding (Kemoli 2010). The remaining studies stated that they received industry funding (Ammann 2013) or non-industry funding (Carvalho 2010).

\section{Characteristics of the participants}

The trials included 1270 participants (among which 233 participants were lost to follow-up) with different age ranges and receiving various restorative treatments. Ammann 2013 included 72 children aged 5.9 to 11.9 years who undertook fissure sealing of premolars or molars. Ma 2012 studied 162 participants (162 teeth) with non-carious cervical lesions (NCCLs) receiving resin composite restoration, without mentioning the age range and sex ratio. Two studies included children undertaking proximal primary atraumatic restorative treatment (ART) restorations in primary molars. These two studies included 804 children aged six to eight years (Kemoli 2010), and 232 children aged six to seven years (Carvalho 2010). All the participants of these included studies received direct dental restorative treatments.

\section{Characteristics of the interventions}

The active intervention in each of the included trials was rubber dam isolation in dental restorative treatments. All of the included trials used a comparison group of cotton rolls as the alternative isolation method.

\section{Characteristics of the outcome measures}

None of the included studies reported both primary outcomes. Three studies reported the survival rate or failure rate of the restorations (Additional Table 2) (Carvalho 2010; Kemoli 2010; Ma 2012). There was variability between the studies in their criteria for "survival or failure of the restorations". Carvalho 2010 and Kemoli 2010 defined "survival of the restorations" as the restorations being present with marginal defects $0.5 \mathrm{~mm}$ or less in depth and general wear $0.5 \mathrm{~mm}$ or less in depth at the deepest point. Ma 2012 defined "failure" as the restoration being absent at the time of evaluation. None of the three studies reported adverse effects. Ammann 2013 did not report survival rate or adverse effects.

None of the included studies evaluated the quality of the restorations, the direct cost of the treatment or the level of participant acceptance/satisfaction. Ammann 2013 evaluated the treatment time when using rubber dam or cotton rolls as the isolation method in fissure sealing.

\section{Excluded studies}

We listed all the excluded studies and the reasons for their exclusion in the Characteristics of excluded studies table.

Six studies were controlled clinical trials (CCT) (Ganss 1999; Huth 2004; Sabbagh 2011; Smales 1993; Straffon 1985; van Dijken 1987). Three studies used either an inappropriate study design or an inappropriate statistical analysis (Daudt 2013; Fontes 2009; Raskin 2000). Daudt 2013 and Raskin 2000 performed randomisation and analysis at the tooth level without accounting for the clustering effect of teeth within individual participants. For Fontes 2009, the study claimed to be performed using a split-mouth design, but it was not carried out it in an appropriate way.

\section{Risk of bias in included studies}

All of the included studies were at high risk of bias overall, based on a judgement of high risk of bias for two domains (Ammann 2013; Carvalho 2010; Kemoli 2010), or one domain (Ma 2012).

Details of the assessments made of these studies are available in the 'Risk of bias' section of the Characteristics of included studies table and in the 'Risk of bias' graph (Figure 2) and 'Risk of bias' summary (Figure 3 ). 
Figure 2. Risk of bias graph: review authors' judgements about each risk of bias item presented as percentages across all included studies.

Random sequence generation (selection bias)

Allocation concealment (selection bias)

Blinding of participants and personnel (performance bias)

Blinding of outcome assessment (detection bias)

Incomplete outcome data (attrition bias)

Selective reporting (reporting bias)

Other bias

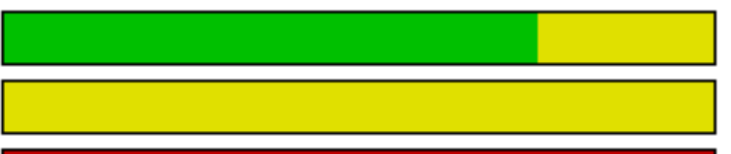

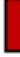

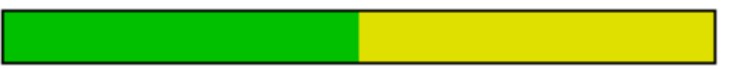

L
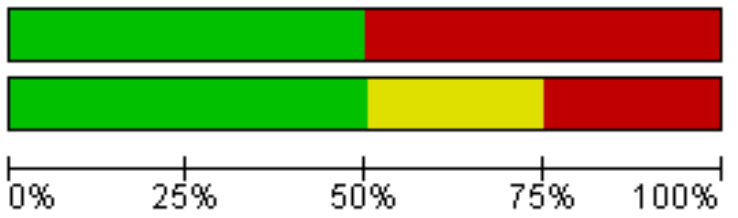

Low risk of bias

Unclear risk of bias

High risk of bias 
Figure 3. Risk of bias summary: review authors' judgements about each risk of bias item for each included study.

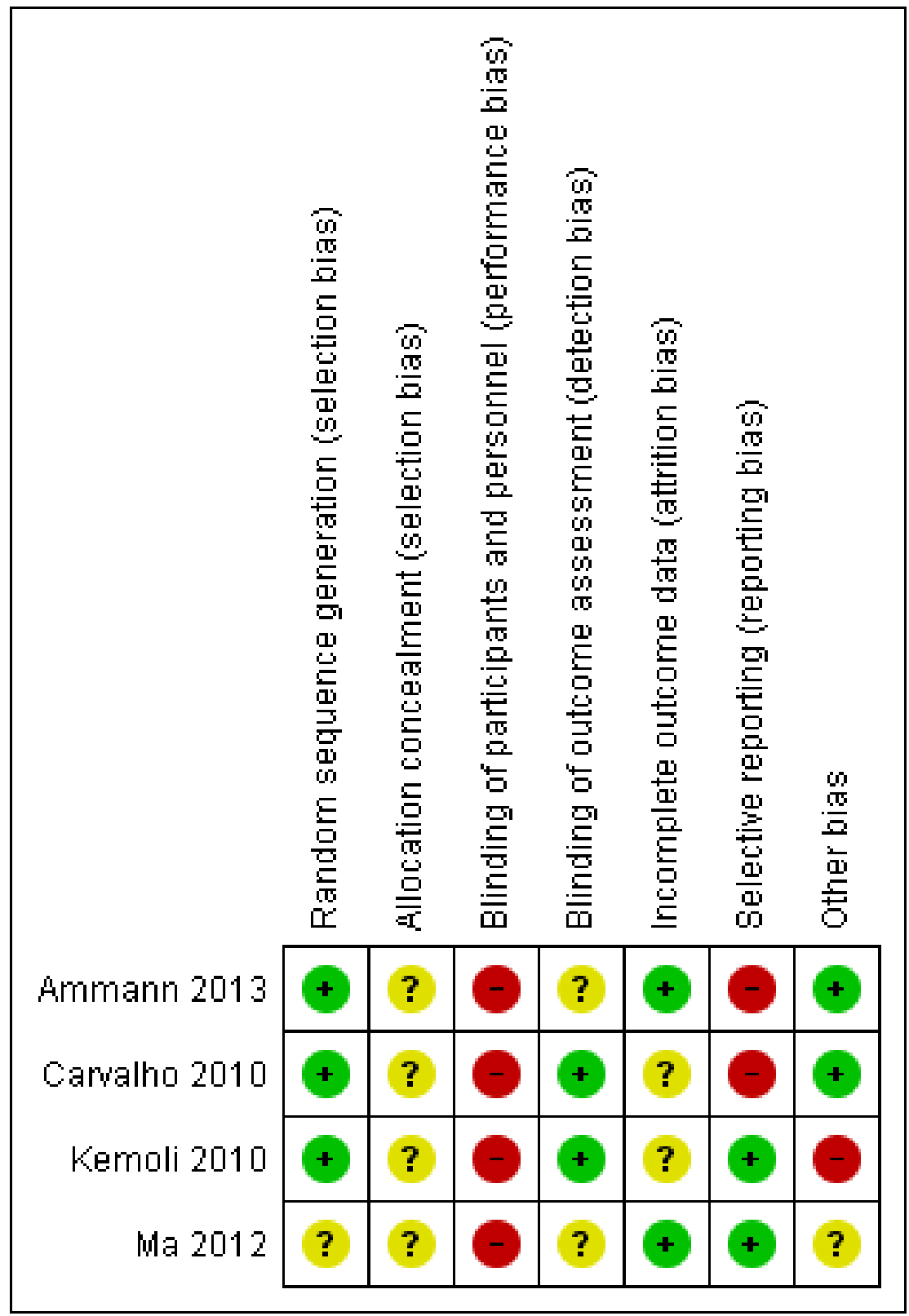

\section{Allocation}

\section{Method of randomisation}

Ammann 2013, Carvalho 2010, and Kemoli 2010 clearly stated the methods of randomisation used in the references. Thus, we assessed these three studies at low risk of bias. We judged Ma 2012 at unclear risk of bias in its method of randomisation, because there was insufficient information to make a clear judgement.

\section{Allocation concealment}

We were unable to make a judgement of high or low risk of bias for allocation concealment as it was not adequately reported in the included studies (Ammann 2013; Carvalho 2010; Kemoli 2010; Ma 2012).

\section{Blinding}

We judged all of the included studies at high risk of performance bias, because the types of interventions did not permit blinding of the operators or the participants (Ammann 2013; Carvalho 2010; Kemoli 2010; Ma 2012).

We assessed two studies at low risk of detection bias (Carvalho 2010; Kemoli 2010). In Carvalho 2010, they explicitly reported the blinding of outcome assessors; and in Kemoli 2010, as the authors clearly stated that the outcome assessors were calibrated and were not the operators, we believed that the outcome assessors had high possibility of being blinded. The remaining studies were at unclear risk of bias in the blinding of outcome assessment, because they did not mention the blinding of outcome assessors (Ammann 2013; Ma 2012). 


\section{Incomplete outcome data}

We judged attrition bias as being low in two studies, because they reported no losses to follow-up (Ammann 2013; Ma 2012). Kemoli 2010 reported that $19.1 \%$ of the participants were lost to follow-up, but did not provide information about the distribution of attrition between treatment groups. Thus, we assessed this study as having an unclear risk of bias for this domain. We also judged Carvalho 2010 at unclear risk of bias, because the reasons for the exclusions of participants were not fully described even though the number of exclusions in each group was comparable $(14.7 \%$ in the control group and $18.5 \%$ in the rubber dam group). The cut-off points used for deciding the risk of attrition bias may be subjective; therefore, readers of this review could interpret the risk of bias for this domain differently.

\section{Selective reporting}

We considered two studies as being at high risk of bias in reporting data (Ammann 2013; Carvalho 2010). In Ammann 2013, the authors did not fully report the data on the treatment time in fissure sealing; and in Carvalho 2010, as the survival/failure rate was not consistent with the number of restorations considered as success or failure presented, we were unable to use the data for analysis. We assessed the studies of Kemoli 2010 and Ma 2012 at low risk of bias for reporting bias, because they fully reported all the prespecified outcomes.

\section{Other potential sources of bias}

Ma 2012 did not report the characteristics of participants to allow an assessment of the comparability of the treatment and control groups at baseline. Thus, we judged this study at unclear risk of bias for this domain. We considered Ammann 2013 and Carvalho 2010 at low risk of bias for other potential sources of bias, because they reported the comparability of the treatment and control groups at baseline. In Kemoli 2010, there was a substantial baseline imbalance in the dental arch between rubber dam and cotton roll isolation groups, which might have influenced the performance of the restorations, so we assessed this study at high risk of bias for other potential sources of bias.

\section{Effects of interventions}

See: Summary of findings for the main comparison Rubber dam versus cotton rolls for restorative treatment in dental patients

\section{Rubber dam versus cotton rolls}

Four studies, at high risk of bias, compared rubber dam isolation method with cotton rolls as the alternative isolation method, and evaluated 1037 participants.

\section{Primary outcomes}

\section{Survival rate of the restorations}

Three studies reported the survival/loss rate of the restorations (Additional Table 2). One study reported the loss rate of the restorations (Ma 2012). The analysis indicated that rubber dam usage resulted in a higher retention rate of restorations in participants with NCCLs receiving resin composite restorative treatment at six months (risk ratio (RR) 1.19, 95\% confidence interval (CI) 1.04 to $1.37,162$ participants, very low-quality evidence) (Analysis 1.1). Two studies reported the survival rates of the restoration (Carvalho 2010; Kemoli 2010). Carvalho 2010 reported the cumulative survival rate of dental restorations at 6,12 , 18 and 24 months. However, the number of restorations reported to have been performed at the start of the evaluation period and the number of restorations failed at the end of the evaluation period were not consistent with the reported survival rate. Due to these inconsistencies, we were unable to include the data of this study in our analyses. Kemoli 2010 found a significant difference in the survival rate of dental restorations was observed at two years in favour of rubber dam usage (hazard ratio (HR) $0.80,95 \% \mathrm{Cl} 0.66$ to $0.97,559$ participants, very low-quality evidence) (Analysis 1.2).

\section{Adverse events}

None of the included studies reported adverse events.

\section{Secondary outcomes}

Clinical evaluation of restoration's quality

None of the included studies evaluated the quality of the restorations.

\section{Costs}

One study, at high risk of bias evaluating 72 children, reported $12.4 \%$ less time ( 108 seconds) needed to accomplish fissure sealing using rubber dam compared to using cotton rolls as the isolation method (Ammann 2013). None of the included studies reported the direct cost of treatment.

\section{Participant acceptance/satisfaction}

None of the included studies reported the level of participant acceptance/satisfaction.

\section{DISCUSSION}

\section{Summary of main results}

Four studies met the inclusion criteria for this review, and all of these studies evaluated the effects of rubber dam versus cotton roll isolation methods on the direct restorative treatments in dental patients, including fissure sealing in permanent premolars or molars, proximal atraumatic restorative treatment (ART) in primary molars and composite resin restoration of non-carious cervical lesions (NCCLs) in permanent teeth. We assessed the quality of the body of evidence based upon the GRADE approach, which takes into account the risk of bias of the included studies, the directness of the evidence, the consistency of the results (heterogeneity), the precision of the effect estimates and the risk of publication bias (GRADE 2004). We have provided a summary of this quality assessment for survival rates at six months and two years (Summary of findings for the main comparison).

There was very low-quality evidence, from single studies, indicating that rubber dam isolation may favour a higher survival rate or a lower loss rate of restorations during dental direct restorative treatments.

- Rubber dam compared with cotton rolls in resin composite restorative treatments of NCCLs (very low-quality evidence) (Ma 2012).

- Rubber dam compared with cotton rolls in proximal ART restorative treatments in primary molars (very low-quality evidence) (Kemoli 2010). 
We did not analyse the data for rubber dam versus cotton rolls in Carvalho 2010, because we found inconsistencies of reported data. Ammann 2013 did not evaluate the survival rate of fissure sealants. None of the included studies reported adverse events.

\section{Overall completeness and applicability of evidence}

The identified studies in the review did not address the objectives of the review sufficiently. Four studies were eligible for inclusion, and they only investigated participants receiving fissure sealing, resin composite restorations of NCCLs and proximal ART restorative treatments. We found no eligible randomised controlled trials (RCTs) of participants receiving other types of restorative treatments such as inlays, onlays, etc. Furthermore, none of the included studies fully reported the outcomes and the evidence was incomplete regarding the outcomes. There were no included studies evaluating the quality of the restorations or reporting adverse effects, the direct cost of the treatment, or the level of participant acceptance/satisfaction, which are important aspects in rubber dam usage (Hill 2008; Koshy 2002; Stewardson 2002). Although three of the included studies reported the survival/loss rate, we could not pool the outcomes to address this primary outcome due to inconsistent data presentation, differences in the restorative treatments carried out, different follow-up time points, or different criteria used for the definition of 'survival/failure' among them.

\section{Quality of the evidence}

The body of evidence that we identified did not allow for robust conclusions about the effects of rubber dam isolation for restorative treatment to be made. We included four studies, which analysed 1037 participants. We excluded one study from analysis due to inconsistencies in the presented data (Carvalho 2010). The remaining three studies were at high risk of bias (Ammann 2013; Kemoli 2010; Ma 2012). When such risk of bias issues were considered alongside the fact that the study in each comparison/ outcome was a single small study (leading to serious imprecision), this resulted in us rating the evidence as very low quality. These GRADE ratings can be interpreted as a lack of confidence in the effect estimates. Further research is likely to change the estimates and our confidence in them.

\section{Potential biases in the review process}

We searched multiple databases with no language restrictions, intending to limit bias by including all relevant studies. However, we did not include all of the included studies into the analysis, and this could introduce bias into the review as it may distort our overall view of the effects of the rubber dam isolation method. Our subjective assessments that a loss to follow-up of more than $20 \%$ constitutes a high attrition rate could also be interpreted as bias by some readers. However, we have presented all the related information, rationales for the method used, and our assessments with the intention of transparency and to allow the readers to reach their own conclusion.

\section{Agreements and disagreements with other studies or reviews}

To our knowledge, one systematic review has studied the influence of different operatory field isolation techniques on the longevity of dental restorations (Cajazeira 2014). Their inclusion criteria differed from the inclusion criteria of this review in that they only included studies evaluating the effects of the operatory field isolation techniques (rubber dam or cotton rolls/saliva ejector) on the longevity of direct restorations performed with tooth-coloured materials in primary or permanent posterior teeth, and having a follow-up period of at least 12 months. Moreover, the Cajazeira 2014 review included two studies that we excluded: Huth 2004, which we excluded since randomised allocation of participants was not performed between the two isolation groups in the study, and Raskin 2000, which we excluded due to inappropriate statistical analysis (randomisation and analysis at tooth level without accounting for the clustering effect of teeth within participants). They finally included four studies into the analysis (Carvalho 2010; Huth 2004; Kemoli 2010; Raskin 2000), and concluded that the use of rubber dam might not influence the longevity of restorations in comparison to using cotton rolls/saliva ejector.

\section{AUTHORS' CONCLUSIONS}

\section{Implications for practice}

We found some very low-quality evidence, from single studies, suggesting that rubber dam usage in dental direct restorative treatments may lead to a higher survival rate of the restorations. The effect estimate should be interpreted with caution due to a high risk of bias in the analysed studies, the small number of included studies and that the type of restorative treatments varied among studies. This review found no evidence to support or refute any adverse effects that the rubber dam isolation method may have on patients.

Although there was no robust evidence to favour rubber dam usage in improving the survival rate of restorations, this does not mean that rubber dam usage is not important during restorative treatments, since the clinical decision is not solely based upon its ability to reduce failure rate of restorations. The use of rubber dam still has numerous advantages, such as preventing accidental swallowing of restorative instruments or tooth fragments, protecting soft tissues from sharp instruments, or helping in behaviour management in children. Clinicians still need to practice rubber dam placement, and never using a rubber dam would not be an acceptable approach.

\section{Implications for research}

The fact that we are unable to make a robust conclusion on the effect of using rubber dam isolation during restorative treatments in dental patients demonstrates that more randomised controlled trials with longer follow-up periods are needed. In particular, we identified no studies that investigated the effects of the isolation methods on the performance of indirect restorations. Further properly designed high quality research is required, as we excluded a few studies due to inappropriate statistical analysis, such as performing randomisation and analysis at tooth level without accounting for the clustering effect of teeth within participants. Studies should report the survival rate of restorations and perform clinical evaluation of the quality of the restorations based upon US Public Health Service criteria. Adverse effects, participant acceptance/satisfaction and the direct cost of the treatment should also be clearly reported at the participant level per group. 


\section{ACK N OWLEDGEMENTS}

We would like to thank Cochrane Oral Health editorial team, external referees (Alison Qualtrough, Patrick Sequeira-Byron and
Trevor Burke), and Consumer Co-ordinator (Ruth Floate) for their help in conducting this systematic review. We would also like to thank Anne Littlewood for designing the search strategy and doing databases searches, and thank Janet Lear for helping with obtaining the full-text articles. 


\section{RE F E R E N C E S}

\section{References to studies included in this review}

Ammann 2013 \{published data only\}

Ammann P, Kolb A, Lussi A, Seemann R. Influence of rubber dam on objective and subjective parameters of stress during dental treatment of children and adolescents - a randomized controlled clinical pilot study. International Journal of Paediatric Dentistry 2013;23(2):110-5.

\section{Carvalho 2010 \{published data only\}}

Carvalho TS, Sampaio FC, Diniz A, Bönecker M, Van Amerongen WE. Two years survival rate of Class II ART restorations in primary molars using two ways to avoid saliva contamination. International Journal of Paediatric Dentistry 2010;20(6):419-25.

\section{Kemoli 2010 \{published data only\}}

Kemoli AM, van Amerongen WE, Opinya GN. Influence of the experience of operator and assistant on the survival rate of proximal ART restorations - two-year results. European Archives of Paediatric Dentistry 2009;10(4):243-8.

* Kemoli AM, van Amerongen WE, Opinya GN. Short communication: Influence of different isolation methods on the survival of proximal ART restorations in primary molars after two years. European Archives of Paediatric Dentistry 2010;11(3):136-9.

\section{Ma 2012 \{published data only\}}

$\mathrm{Ma} \mathrm{J}$. Influence of rubber dam isolation on the performance of restorations for teeth wedge-shaped defects. Chinese Community Doctors 2012;14(309):164.

\section{References to studies excluded from this review}

\section{Daudt 2013 \{published data only\}}

Daudt E, Lopes GC, Vieira LCC. Does the isolation method influence the performance of direct restorations? 89th Genera Session of the International Association for Dental Research. San Diego (CA): International Association for Dental Research, 2011:Abstract no: 1697.

* Daudt E, Lopes GC, Vieira LCC. Does operatory field isolation influence the performance of direct adhesive restorations?. Journal of Adhesive Dentistry 2013;15(1):27-32.

Fontes 2009 \{unpublished data only\}

Fontes ST, Corrêa FOB, Cenci MS, Jardim PS, Pinto MB, Masotti AS. Influence of operatory field isolation techniques on the clinical performance of class $V$ restorations. clinicaltrials.gov/ct2/show/NCT01506830 Date first received 30 December 2011.

\section{Ganss 1999 \{published data only\}}

Ganss C, Klimek J, Gleim A. One year clinical evaluation of the retention and quality of two fluoride releasing sealants. Clinical Oral Investigations 1999;3:188-93.
Huth 2004 \{published data only\}

Huth KC, Manhard J, Hickel R, Kunzelmann K. Three-year clinical performance of a compomer in stress-bearing restorations in permanent posterior teeth. American Journal of Dentistry 2003;16(4):255-9.

* Huth KC, Manhard J, Selbertinger A, Paschos E, Kaaden C, Kunzelmann $\mathrm{K}$, et al. 4-year clinical performance and survival analysis of Class I and II compomer restorations in permanent teeth. American Journal of Dentistry 2004;17(1):51-5.

\section{Raskin 2000 \{published data only\}}

Raskin A, Setcos JC, Vreven J, Wilson NHF. Clinical evaluation of a posterior composite 10-year report. Journal of Dentistry 1999;27:13-9.

* Raskin A, Setcos JC, Vreven J, Wilson NHF. Influence of the isolation method on the 10-year clinical behaviour of posterior resin composite restorations. Clinical Oral Investigations 2000;4(3):148-52.

\section{Sabbagh 2011 \{published data only\}}

Sabbagh J, Dagher S, El-Osta N, Souhaid P. One year clinical evaluation of vertise flow. 45th Meeting of the Continental European Division of the International Association of Dental Research; 2011 Aug 31-Sept 3; Budapest, Hungary. Alexandria, VA: International Association for Dental Research, 2011:Abstract no: 232.

Smales 1993 \{published data only\}

Smales RJ. Effect of rubber dam isolation on restoration deterioration. American Journal of Dentistry 1992;5(5):277-9.

* Smales RJ. Rubber dam usage related to restoration quality and survival. British Dental Journal 1993;174(9):330-3.

\section{Straffon 1985 \{published data only\}}

Straffon LH, Dennison JB, More FG. Three-year evaluation of sealant: effect of isolation on efficacy. Journal of the American Dental Association 1985;110(5):714-7.

\section{van Dijken 1987 \{published data only\}}

van Dijken JWV, Hörstedt P. Effect of the use of rubber dam versus cotton rolls on marginal adaptation of composite resin fillings to acid-etched enamel. Acta Odontologica Scandinavica 1987;45:303-8.

\section{References to studies awaiting assessment}

Alhareky 2014 \{published data only\}

Alhareky MS, Mermelstein D, Finkelman M, Alhumaid J, Loo C. Efficiency and patient satisfaction with the Isolite system versus rubber dam for sealant placement in pediatric patients. Pediatric Dentistry 2014;36(5):400-4. 


\section{Additional references}

\section{Atkins 2004}

Atkins D, Best D, Briss PA, Eccles M, Falck-Ytter Y, Flottorp S, et al. Grading quality of evidence and strength of recommendations. BMJ 2004;328(7454):1490.

\section{Begg 1994}

Begg CB, Mazumdar M. Operating characteristics of a rank correlation test for publication bias. Biometrics 1994;50(4):1088-101.

\section{Bhuva 2008}

Bhuva B, Chong BS, Patel S. Rubber dam in clinical practice. Endodontic Practice Today 2008;2(2):131-41.

\section{Cajazeira 2014}

Cajazeira MR, De Sabóia TM, Maia LC. Influence of the operatory field isolation technique on tooth-colored direct dental restorations. American Journal of Dentistry 2014;27(3):155-9.

\section{Carrotte 2000}

Carrotte PV. Current practice in endodontics: 3 . Access is success, and rubber dam is easy. Dental Update 2000;27(9):436-40.

\section{Carrotte 2004}

Carrotte P. Endodontics: Part 6 Rubber dam and access cavities. British Dental Journal 2004;197(9):527-34.

\section{Cochran 1989}

Cochran MA, Miller $\mathrm{CH}$, Sheldrake MA. The efficacy of the rubber dam as a barrier to the spread of microorganisms during dental treatment. Journal of the American Dental Association 1989;119(1):141-4.

\section{Cohen 1987}

Cohen S, Schwartz S. Endodontic complications and the law. Journal of Endodontics 1987;13(4):191-7.

\section{Egger 1997}

Egger M, Davey Smith G, Schneider M, Minder C. Bias in meta-analysis detected by a simple, graphical test. BMJ 1997;315(7109):629-34.

\section{Elderton 1971a}

Elderton RJ. A modern approach to use of rubber dam. 1. Dental Practitioner and Dental Record 1971;21(6):187-93.

\section{Elderton 1971b}

Elderton RJ. A modern approach to use of rubber dam. 2. Dental Practitioner and Dental Record 1971;21(7):226-32.

\section{Elderton 1971c}

Elderton RJ. A modern approach to use of rubber dam. 3. Dental Practitioner and Dental Record 1971;21(8):267-73.

\section{GRADE 2004}

GRADE Working Group. Grading quality of evidence and strength of recommendations. BMJ 2004;328(1490):1-8.

\section{GRADEproGDT [Computer program]}

GRADE Working Group, McMaster University. GRADEproGDT. Version accessed August 2016. Hamilton (ON): GRADE Working Group, McMaster University, 2014.

\section{Guyatt 2008}

Guyatt GH, Oxman AD, Vist GE, Kunz R, Falck-Ytter Y, AlonsoCoello $P$, et al. GRADE: an emerging consensus on rating quality of evidence and strength of recommendations. BMJ 2008;336(7650):924-6.

\section{Halbach 2008}

Halbach S, Vogt S, Köhler W, Felgenhauer N, Welzl G, Kremers L, et al. Blood and urine mercury levels in adult amalgam patients of a randomized controlled trial: interaction of $\mathrm{Hg}$ species in erythrocytes. Environmental Research 2008;107(1):69-78.

\section{Harrel 2004}

Harrel SK, Molinari J. Aerosols and splatter in dentistry: a brief review of the literature and infection control implications. Journal of the American Dental Association 2004;135(4):429-37.

\section{Hickel 2007}

Hickel R, Roulet JF, Bayne S, Heintze SD, Mjör IA, Peters M, et al. Recommendations for conducting controlled clinical studies of dental restorative materials. Clinical Oral Investigations 2007;11(1):5-33.

\section{Higgins 2011}

Higgins JPT, Green S (editors). Cochrane Handbook for Systematic Reviews of Interventions version 5.1.0 (updated March 2011). The Cochrane Collaboration, 2011. Available from www.cochrane-handbook.org.

\section{Hill 2008}

Hill EE, Rubel BS. Do dental educators need to improve their approach to teaching rubber dam use?. Journal of Dental Education 2008;72(10):1177-81.

\section{Koshy 2002}

Koshy S, Chandler NP. Use of rubber dam and its association with other endodontic procedures in New Zealand. New Zealand Dental Journal 2002;98(431):12-6.

\section{Kremers 1999}

Kremers L, Halbach S, Willruth H, Mehl A, Welzl G, Wack FX, et al. Effect of rubber dam on mercury exposure during amalgam removal. European Journal of Oral Sciences 1999;107(3):202-7.

\section{Lynch 2003}

Lynch CD, McConnell RJ. The use of microabrasion to remove discolored enamel: a clinical report. Journal of Prosthetic Dentistry 2003;90:417-9.

\section{Mamoun 2002}

Mamoun J. A prosthesis for achieving dry-field isolation of molars with short clinical crowns. Journal of the American Dental Association 2002;133(8):1105-7. 


\section{Parmar 1998}

Parmar MK, Torri V, Stewart L. Extracting summary statistics to perform meta-analysis of the published literature for survival endpoints. Statistics in Medicine 1998;17(24):2815-34.

\section{Perrine 2005}

Perrine GA. A simplified rubber-dam technique for preparing teeth for indirect restorations. Journal of the American Dental Association 2005;136(11):1560-1.

\section{Reid 1991}

Reid JS, Callis PD, Patterson CJW. Rubber Dam in Clinical Practice. 1st Edition. London: Quintessence Publishing, 1991.

\section{Reuter 1983}

Reuter JE. The isolation of teeth and the protection of patient during endodontic treatment. International Endodontic Journal 1983;16(4):173-81.

\section{Stewardson 2002}

Stewardson DA, McHugh ES. Patients' attitudes to rubber dam. International Endodontic Journal 2002;35(10):812-9.

\section{Susini 2007}

Susini G, Pommel L, Camps J. Accidental ingestion and aspiration of root canal instruments and other dental foreign bodies in a French population. International Endodontic Journal 2007;40(8):585-9.

\section{Sutton 1996}

Sutton J, Saunders WP. Effect of various irrigant and autoclaving regimes on the fracture resistance of rubber dam clamps. International Endodontic Journal 1996;29(5):335-43.

\section{Tiwana 2004}

Tiwana KK, Morton T, Tiwana PS. Aspiration and ingestion in dental practice: a 10-year institutional review. Journal of the American Dental Association 2004;135(9):1287-91.

* Indicates the major publication for the study

\section{CHARACTERISTICS OF STUDIES}

Characteristics of included studies [ordered by study ID]

Ammann 2013

$\begin{array}{ll}\text { Methods } & \text { Design: parallel-group RCT } \\ & \text { Recruitment period: not stated } \\ \text { Administration setting: private dental clinic } \\ \text { Country: Germany } \\ \text { Funding source: Dentsply DeTrey, Konstanz, Germany }\end{array}$

Participants

Number of participants randomised: 72 (rubber dam: 34; cotton rolls: 38)

Randomisation unit: participant

Age: 5.9 to 16.9 years, mean age 11.1 years

Sex: 23 boys, 49 girls

Inclusion criteria:

- aged 6 to 16 years

- given indication for fissure sealing

Exclusion criteria:

- participation in other studies evaluating parameters of stress

- not totally erupted teeth to seal

- lack of compliance

- no agreement from the guardians

- presence of fixed orthodontic appliances

- signs of opacity and brown discolouration of the tooth to be sealed

- psychotropic medication or cardiovascular drugs

- already sealed teeth 
Ammann 2013 (Continued)

$$
\begin{aligned}
& \text { - present disease (cold) } \\
& \text { - allergic reactions to used materials }
\end{aligned}
$$

Restorative treatments received: fissure sealing in premolar/molar

Number of participants evaluated: 72 (rubber dam: 34; cotton rolls: 38 )

Withdrawals/loss to follow-up: no withdrawals

Number of groups: 2
Interventions
Gervention: rubber dam: "A suitable rubber dam clamp (Ivoryò; Sigma Dental Systems, Handewitt,
teeth were included in the rubber dam in cases involving premolars, whereas for molars only the treat-
ed tooth was isolated"
Control: cotton rolls: "The cotton rolls were positioned on the buccal and lingual region of the tooth to
be sealed and were fixed by the operator's index finger and middle finger. Additionally, a saliva ejector
was placed on the lingual side"

Outcomes Outcomes: treatment time

Notes Adverse events: not stated

No details on sample size or power calculation were provided

\section{Risk of bias}

\begin{tabular}{lll}
\hline Bias & Authors' judgement & Support for judgement \\
\hline $\begin{array}{ll}\text { Random sequence genera- } \\
\text { tion (selection bias) }\end{array}$ & Low risk & $\begin{array}{l}\text { Quote: "72 subjects successfully took part in the study and were divided into } \\
\text { two parallel groups by a dental assistant by drawing sealed lots (test } n=34 ; \\
\text { control } n=38) "\end{array}$ \\
& & Comment: method stated and appropriate
\end{tabular}

\begin{tabular}{lll}
\hline $\begin{array}{l}\text { Allocation concealment } \\
\text { (selection bias) }\end{array}$ & Unclear risk & Not stated \\
& Comment: insufficient information reported to make a judgement \\
\hline
\end{tabular}

Blinding of participants High risk Comment: the operators and the participants could not be blinded
and personnel (perfor-

mance bias)

All outcomes

\begin{tabular}{lll}
\hline $\begin{array}{l}\text { Blinding of outcome as- } \\
\text { sessment (detection bias) } \\
\text { All outcomes }\end{array}$ & Unclear risk & $\begin{array}{l}\text { Not stated } \\
\text { Comment: insufficient information reported to make a judgement }\end{array}$ \\
\hline $\begin{array}{l}\text { Incomplete outcome data } \\
\text { (attrition bias) } \\
\text { All outcomes }\end{array}$ & Low risk & Comment: no withdrawals \\
\hline $\begin{array}{l}\text { Selective reporting (re- } \\
\text { porting bias) }\end{array}$ & High risk & $\begin{array}{l}\text { Quote: "The time needed to finish the fissure sealing treatment was } 12.4 \%(108 \\
\text { s [seconds]) less when using rubber dam }(P<0.05) " ~ \\
\text { Comment: insufficient information reported to use the data in the analysis }\end{array}$ \\
\hline
\end{tabular}

Other bias Low risk Comparable groups at baseline (age, gender, type of teeth treated)


Carvalho 2010

Design: parallel-group RCT
Recruitment period: not stated
Administration setting: schools
Country: Brazil
Funding source: the Coordenação de Aperfeiçoamento de Pessoal de Nível Superior (CAPES)

Participants

Number of participants randomised: 232; 232 teeth (rubber dam: 115; cotton rolls: 117)

Randomisation unit: participant/tooth

Age: 6 to 7 years, mean age 6.3 years

Sex: 128 boys, 104 girls

Inclusion criteria:

- aged 6 to 7 years

- proximal lesions having access to ART hand instruments, with a mesio-distal maximum dimension of $1 \mathrm{~mm}$ and a buccal-lingual maximum dimension of $2 \mathrm{~mm}$ length, measured on the occlusal surface using a periodontal probe

- lesions with unimpaired adjacent tooth

Exclusion criteria:

- cavitated carious lesions having pulpal involvement, swelling, fistula or pain

Restorative treatments received: proximal ART restorations in primary molar

Number of participants evaluated: 155 (rubber dam: 72 teeth; cotton rolls: 83 teeth)

Withdrawals/loss to follow-up: 77 children in total. 48 children were unavailable at the time of assessment. 29 children lost their teeth due to exfoliation or extraction

Interventions Number of groups: 2

Intervention: rubber dam: "For the experiment group, a rubber dam was used, fixed with a clamp on the adjacent distal tooth without local anaesthesia"

Control: cotton rolls: "New cotton rolls were placed on both sides of the molar without local anaesthesia"

Outcomes Outcomes: failure rate/cumulative survival rate of restorations

Time points: $6,12,18$ and 24 months after restoration placement

Diagnostic criteria: restorations assessed according to the following criteria:

- successful treatment: when it was still present and correct or having only a slight wear or defect at the margin $<0.5 \mathrm{~mm}$ in depth

- treatment failures: when the restorations were either completely lost, or were fractured with defects $\geq 0.5 \mathrm{~mm}$ in depth, had secondary caries, or inflammation of the pulp

- lost to follow-up: when the children who were not found at the time of assessment, or when the teeth were lost to exfoliation or extraction 
No details on sample size or power calculation provided

The survival/failure rate was not consistent with the number of restorations considered as success or failure presented in table 1 of the report. We were unable to use the data in the analysis

\section{Risk of bias}

\section{Bias Authors' judgement Support for judgement}

Random sequence genera- Low risk tion (selection bias)
Quote: "Each child was individually allocated into a group by the use of generated random numbers, and no restrictions were considered"

Comment: method stated and appropriate
Quote: "Each child was individually allocated into a group by the use of generated random numbers, and no restrictions were considered. The group in charge of making the restorations or those who assessed the restorations did not have access to the randomizations procedure. All children were allocated into the respective group before the restorations were made"

Comment: sequence allocation was not adequately described

Blinding of participants High risk Comment: the operators and the participants could not be blinded
and personnel (perfor-
mance bias)
All outcomes

\section{Blinding of outcome as- Low risk} sessment (detection bias)

All outcomes
Quote: "These examiners were blinded to the exposure categories. In other words, at the time of examination of the restoration, the examiners did not know to which group the child belonged to"

Comment: examiners were blinded
Incomplete outcome data Unclear risk (attrition bias)

All outcomes
Quote: "Throughout the study, a total of 48 (20.7\%) children were considered as lost to follow-up. Others eventually lost their teeth due to exfoliation or extraction. Due to such reasons, a total of 77 restorations (33.2\%) were censored (lost to follow-up), where 34 (14.7\%) were from the control group and 43 $(18.5 \%)$ from the rubber dam group $\left(\mathrm{X}^{2}\left[\mathrm{Chi}^{2}\right]=1.82 ; \mathrm{df}\right.$ [degrees of freedom] $=$ $1 ; \mathrm{P}=0.18)^{\prime \prime}$

Comment: loss to follow-up was high (overall $33.2 \%$ ) and reasons for loss to follow-up (20.7\%) were not explicitly explained

\begin{tabular}{lll}
\hline $\begin{array}{l}\text { Selective reporting (re- } \\
\text { porting bias) }\end{array}$ & High risk & $\begin{array}{l}\text { Comment: survival/failure rate was not consistent with the number of restora- } \\
\text { tions considered as success or failure presented in table 1. We were unable to } \\
\text { use the data in the analysis }\end{array}$ \\
\hline Other bias & Low risk & $\begin{array}{l}\text { Comment: groups at baseline (age, gender, jaw, molar and operator) compara- } \\
\text { ble }\end{array}$ \\
\hline
\end{tabular}

Kemoli 2010

\begin{tabular}{ll}
\hline Methods & Design: parallel-group RCT \\
& Recruitment period: not stated \\
Administration setting: public primary schools \\
Country: Kenya \\
\hline
\end{tabular}


Kemoli 2010 (Continued)

Funding source: Netherlands Universities' Foundation for International Cooperation (NUFFIC), financial support from the University of Nairobi, GC Europe and 3M ESPE (Netherlands)

Participants

Number of participants randomised: 804; 804 teeth (rubber dam: 404; cotton rolls: 397 )

Randomisation unit: participant/tooth

Age: 6 to 8 years

Sex: 454 boys, 350 girls

Inclusion criteria:

- aged 6 to 8 years

- in good general health

- a proximal carious lesion in a primary molar having an occlusal access of approximately $0.5 \mathrm{~mm}$ to 1.0 $\mathrm{mm}$ in the bucco-lingual direction

Exclusion criteria: not stated

Restorative treatments received: proximal ART restorations in primary molars. Fuji IX (GC Europe) or Ketac Molar Easymix or KME (3M ESPE AG); Ketac Molar Aplicap or KMA (3M ESPE AG)

Number of participants evaluated: 648 (number in each group not stated)

Withdrawals/loss to follow-up:

- overall $156(19.4 \%)$

- $3(0.4 \%)$ cases that were improperly documented

- $38(4.7 \%)$ could not be evaluated after placement because of truancy

- 115 (14.3\%) withdrawals due to drop-outs, school-transferees, absentees and 1 death

Interventions

Number of groups: 2

Intervention: rubber dam: "The rubber dam (Medium-dark, Hygenic Dental Dam, HCM - Hygienic Corporation, Malaysia) was used to isolate the tooth to be restored. A 2-minute gingival application of a topical anaesthetic (Lidocaine $50 \mathrm{mg} / \mathrm{g}$ cream) was used prior to the application of the rubber dam clamp (FIT - Kofferdam Klammer, U67, Hager \& Werken GmbH \& Co. KG Germany). No other local analgesic was used in the study"

Control: cotton rolls: "The cotton wool rolls were place buccally (maxillary teeth) or lingually and buccally (mandibular teeth)"

Outcomes: survival rate of restorations
Time points: within 2 hours of restoring each tooth, after 1 week, and $1,5,12,18$ and 24 months after
the restoration
Diagnostic criteria: restorations categorised as 0,1 and 6 had survived; $2,3,7,9$ had failed; and 4,5 and
8 were censored. $0=$ present, good. $1=$ present, marginal defects $\leq 0.5 \mathrm{~mm}$ in depth. $2=$ present with
marginal defects $>0.5 \mathrm{~mm}$ deep. $3=$ not present, restoration almost or completely disappeared. $4=$
not present, other restoration present. $5=$ not present, tooth extracted/exfoliated. $6=$ present, general
wear over the restoration of $\leq 0.5 \mathrm{~mm}$ at the deepest point. $7=$ present, general wear over the restora-
tion of $>0.5 \mathrm{~mm} .8=$ undiagnosable. $9=$ presence of secondary caries in relation to restoration

Notes Adverse events: not stated

Sample size: calculated sample size was 382, but no details provided

\section{Risk of bias}


Kemoli 2010 (Continued)

Random sequence genera- Low risk Quote: "Using random numbers, the children were assigned to an isolation tion (selection bias) method, material, operator and assistant. Each child had the restoration randomly placed in the primary molar in either mandibular or maxillary arch"

Comment: method stated and appropriate

\begin{tabular}{ll}
\hline $\begin{array}{l}\text { Allocation concealment } \\
\text { (selection bias) }\end{array}$ & Unclear risk \\
& Comment: insufficient information reported to make a judgement
\end{tabular}

Blinding of participants High risk Comment: operators and participants could not be blinded
and personnel (performance bias)

All outcomes

\begin{tabular}{|c|c|c|}
\hline $\begin{array}{l}\text { Blinding of outcome as- } \\
\text { sessment (detection bias) }\end{array}$ & Low risk & $\begin{array}{l}\text { Quote: "The evaluators had not restored the cavities but had been trained and } \\
\text { calibrated in the technique" }\end{array}$ \\
\hline All outcomes & & Comment: operators were not the assessors \\
\hline
\end{tabular}

All outcomes

Comment: operators were not the assessors

Incomplete outcome data Unclear risk
(attrition bias)

Quote: "Save for 3 cases that were improperly documented. Because of truanAll outcomes cy $38(4.7 \%)$ of the restorations the 801 documented cases could not be evaluated soon after placement, leaving only 763 restorations to be evaluated. Due to the study-population attrition resulting from drop-outs, school-transferees, absentees and one death, only $648(80.9 \%)$ children could be evaluated at the end of 2 years"

Comment: overall losses $<20 \%$, and reasons were listed. However, no details on the number and reasons of withdrawals in each group given

\begin{tabular}{lll}
\hline $\begin{array}{l}\text { Selective reporting (re- } \\
\text { porting bias) }\end{array}$ & Low risk & Comment: outcomes were reported as planned \\
\hline Other bias & High risk & Comment: groups at baseline (dental arch) not comparable \\
& $\begin{array}{l}405 \text { restorations were isolated with rubber dam, } 101 \text { of which were restora- } \\
\text { tions in the mandible; and } 397 \text { were isolated with cotton rolls, } 141 \text { of them } \\
\text { were restorations in the mandible (Fisher's Exact Test, } \mathrm{P}=0.001)\end{array}$ \\
\hline
\end{tabular}

Ma 2012

$\begin{array}{ll}\text { Methods } & \text { Design: parallel-group RCT } \\ & \text { Recruitment period: } 2009 \text { to } 2011 \\ & \text { Administration setting: dental clinical of hospital } \\ \text { Country: China } & \text { Funding source: not stated }\end{array}$

Participants

Number of participants randomised: 162; 162 teeth (rubber dam: 81; cotton rolls: 81 )

Randomisation unit: participant/tooth

Age: not stated

Sex: not stated

Inclusion criteria (as translated): 
Ma 2012 (Continued)

- with NCCLs in mandibular premolars

- in dentine but without pulp exposure

- lesions above the gingival margins

- teeth with NCCLs having no occlusal trauma

- teeth with NCCLs having vital pulps

Exclusion criteria: not stated

Restorative treatments received (as translated): composite restorations of NCCLS

Number of participants evaluated: 162; 162 teeth (rubber dam: 81; cotton rolls: 81 )

Withdrawals/loss to follow-up: no losses to follow-up

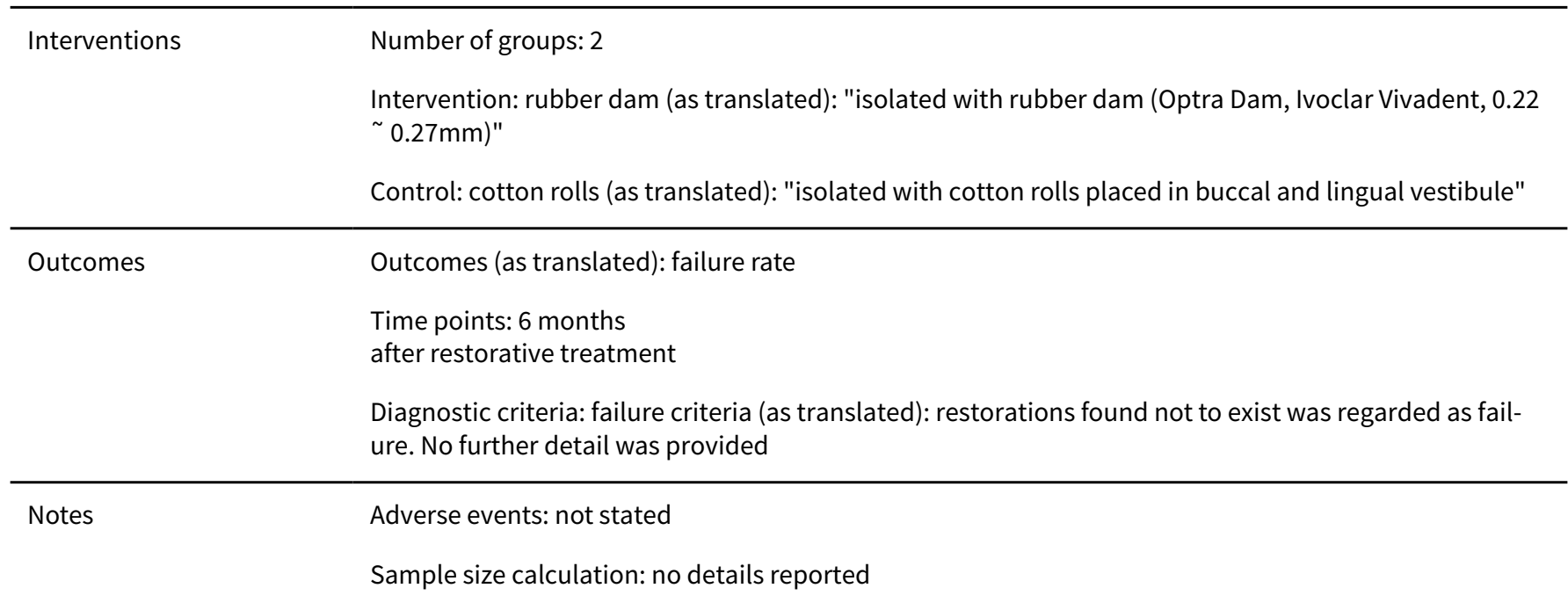

\section{Risk of bias}

\begin{tabular}{lll}
\hline Bias & Authors' judgement & Support for judgement \\
\hline $\begin{array}{l}\text { Random sequence genera- } \\
\text { tion (selection bias) }\end{array}$ & Unclear risk & $\begin{array}{l}\text { Quote (as translated): "One hundred and sixty-two patients with non-carious } \\
\text { cervical lesions were stratified randomly distributed into two groups }(\mathrm{n}=81) \\
\text { from June 2009 to June 2011" }\end{array}$ \\
& $\begin{array}{l}\text { Comment: method of sequence generation not stated. Insufficient information } \\
\text { reported to make a judgement }\end{array}$
\end{tabular}

\begin{tabular}{ll}
\hline $\begin{array}{l}\text { Allocation concealment } \\
\text { (selection bias) }\end{array}$ & Unclear risk \\
& Comment: insufficient information reported to make a judgement \\
\hline
\end{tabular}

Blinding of participants $\quad$ High risk
and personnel (perfor-
mance bias)

\begin{tabular}{lll}
\hline $\begin{array}{l}\text { Blinding of outcome as- } \\
\text { sessment (detection bias) }\end{array}$ & Unclear risk & Not stated \\
$\begin{array}{l}\text { All outcomes } \\
\text { Incomplete outcome data }\end{array}$ & Low risk & Comment: insufficient information reported to make a judgement \\
(attrition bias) & &
\end{tabular}


Ma 2012 (Continued)

All outcomes

Selective reporting (re- Low risk Comment: outcomes reported as planned

porting bias)

Other bias Unclear risk Comment: no data on group comparability

ART: atraumatic restorative treatment; NCCLs: non-carious cervical lesions; RCT: randomised controlled trial.

Characteristics of excluded studies [ordered by study ID]

\begin{tabular}{|c|c|}
\hline Study & Reason for exclusion \\
\hline Daudt 2013 & $\begin{array}{l}\text { Inappropriate statistical analysis (randomisation and analysis at tooth level without accounting for } \\
\text { the clustering effect of teeth within individual participants) }\end{array}$ \\
\hline Fontes 2009 & $\begin{array}{l}\text { Inappropriate study design. The study authors kindly provided us with a prepublication copy of the } \\
\text { study and we were able to see that the study claimed to be performed using a split-mouth design, } \\
\text { but not carried out it in an appropriate way }\end{array}$ \\
\hline Ganss 1999 & $\begin{array}{l}\text { Randomisation allocation not performed between the rubber dam and cotton rolls isolation } \\
\text { groups }\end{array}$ \\
\hline Huth 2004 & $\begin{array}{l}\text { Study was a CCT as randomisation allocation was not performed between the } 2 \text { treatment groups, } \\
\text { and using teeth as the analysis unit }\end{array}$ \\
\hline Raskin 2000 & $\begin{array}{l}\text { Inappropriate statistical analysis (randomisation and analysis at tooth level without accounting for } \\
\text { the clustering effect of teeth within individual participants) }\end{array}$ \\
\hline Sabbagh 2011 & $\begin{array}{l}\text { Conference abstract without mentioning randomisation allocation between the } 2 \text { treatment } \\
\text { groups, and author contact failed }\end{array}$ \\
\hline Smales 1993 & $\begin{array}{l}\text { Study was a CCT as randomisation allocation was not performed between the } 2 \text { treatment groups, } \\
\text { and using teeth as the analysis unit }\end{array}$ \\
\hline Straffon 1985 & $\begin{array}{l}\text { Randomisation allocation not performed between the rubber dam and cotton roll isolation groups } \\
\text { and using tooth surfaces as the analysis unit }\end{array}$ \\
\hline van Dijken 1987 & Study was a CCT as randomisation allocation was not performed between the 2 treatment groups \\
\hline
\end{tabular}

СCT: controlled clinical trial.

Characteristics of studies awaiting assessment [ordered by study ID]

Alhareky 2014

Design: split-mouth
Recruitment period: not reported
Administration setting: teaching clinic of dental school
Country: USA
Funding source: in part by US Department of Health and Human Services Health Resources and
Services Administration grant D84HP19955


Alhareky 2014 (Continued)

Participants
Number of participants randomised: 42; 168 teeth (rubber dam: 84; Isolite system: 84 )

Randomisation unit: teeth

Age: 7 to 16 years, mean age 12.3 years

Sex: 19 boys, 23 girls

Inclusion criteria:

- healthy children with no compromising medical or physical condition

- aged 7 to 16 years

- children with $\geq 1$ caries-free permanent molar in each quadrant, with normal anatomy that qualified for the application of pit and fissure sealants

- co-operative children

Exclusion criteria:

- history of chronic disease

- unable to return for follow-ups

- requiring $<4$ pit and fissure sealants on permanent molars

- children with partially erupted molars

Restorative treatments received: pit and fissure sealing of permanent molar

Number of participants evaluated: 42; 168 teeth (rubber dam: 84; Isolite system: 84)

Withdrawals/loss to follow-up: no loss to follow-up
Interventions
Number of groups: 2

Intervention: RD: "First, gingival soft tissue surrounding the tooth was dried. Topical anesthesia was achieved using 20 percent benzocaine gel, which was applied for one minute, according to the manufacturer's instructions. A wingless clamp appropriate for use on molars was selected and then used in conjunction with a latex-free RD sheet. No bite block was used with the RD"

Control: IS: "First, the isthmus (narrow part in the middle of the IS plastic mouthpiece) was placed at the corner of mouth, and the patient was instructed to open widely. The IS mouthpiece was then inserted while folding the cheek shield forward toward the tongue retractor and sliding the isthmus into the cheek. The patient was asked to bite on the bite block part of the IS. Finally, the cheek shield was tucked into the buccal vestibule, and the tongue retractor was tucked into the tongue vestibule. The high-speed evacuation system was connected to the IS system, and a second highspeed suction was used to evacuate the mouth during the sealant placement application"

Outcomes Treatment time, patient acceptance (evaluated using a questionnaire)

Notes Adverse events: not reported

Sample size calculation: not reported

Awaiting responses from authors on the details of the method of randomisation used, preformation of allocation concealment and funding sources

IS: Isolite system; RD: rubber dam.

\section{DATA AND ANALYSES}


Comparison 1. Rubber dam versus cotton rolls

\begin{tabular}{lllll}
\hline Outcome or subgroup title & $\begin{array}{l}\text { No. of } \\
\text { studies }\end{array}$ & $\begin{array}{l}\text { No. of } \\
\text { partici- } \\
\text { pants }\end{array}$ & Statistical method & Effect size \\
\hline 1 Survival rate (6 months) & 1 & 162 & Risk Ratio (M-H, Fixed, 95\% Cl) & $1.19[1.04,1.37]$ \\
\hline 2 Survival rate (24 months) & 1 & 559 & Hazard Ratio (Fixed, 95\% Cl) & $0.80[0.66,0.97]$ \\
\hline
\end{tabular}

Analysis 1.1. Comparison 1 Rubber dam versus cotton rolls, Outcome 1 Survival rate (6 months).

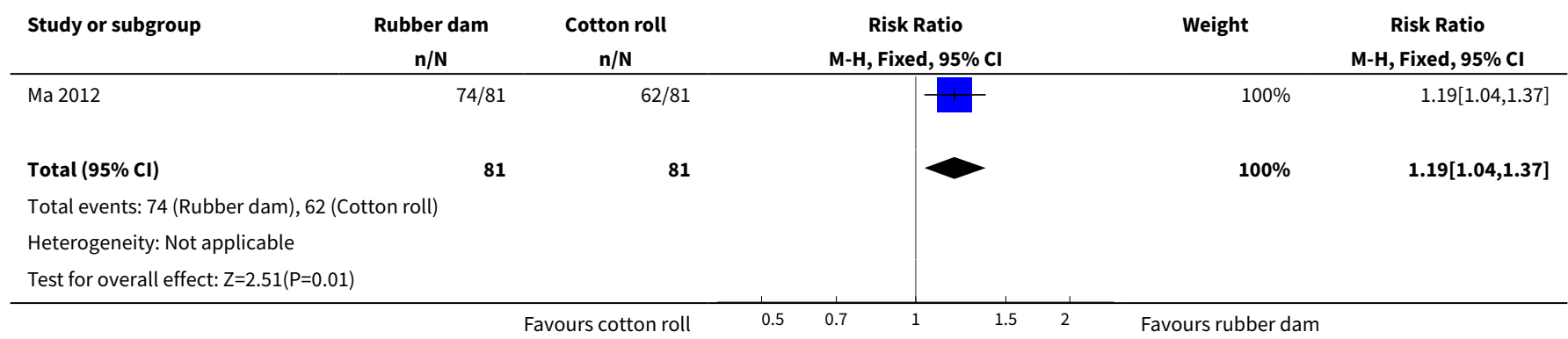

Analysis 1.2. Comparison 1 Rubber dam versus cotton rolls, Outcome 2 Survival rate (24 months).

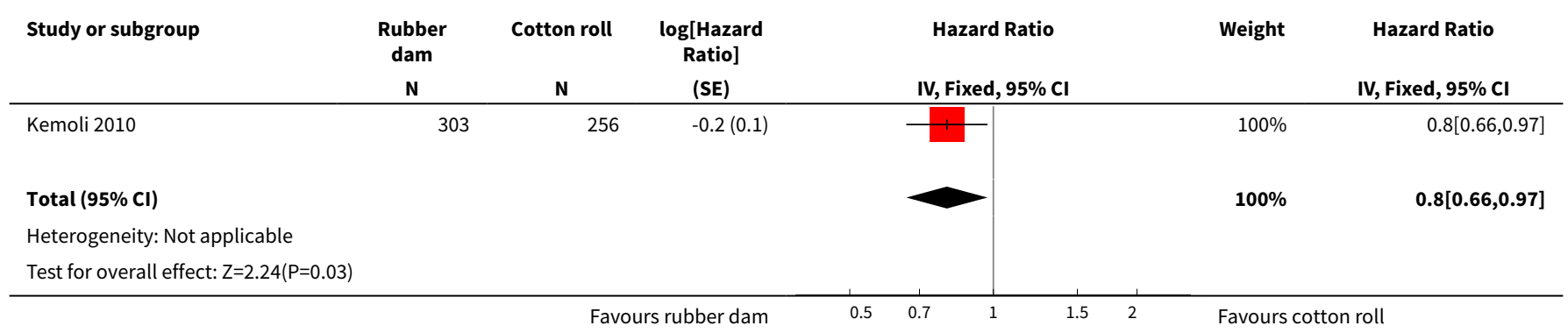

ADDITIONAL TABLES

Table 1. Category of overall risk of bias

\begin{tabular}{llll}
\hline Risk of bias & Interpretation & Within a study & Across studies \\
\hline $\begin{array}{l}\text { Low risk of } \\
\text { bias }\end{array}$ & $\begin{array}{l}\text { Plausible bias unlikely to seriously al- } \\
\text { ter the results }\end{array}$ & $\begin{array}{l}\text { Low risk of bias for all } \\
\text { key domains }\end{array}$ & $\begin{array}{l}\text { Most information is from studies at low risk of } \\
\text { bias }\end{array}$ \\
\hline $\begin{array}{l}\text { Unclear risk } \\
\text { of bias }\end{array}$ & $\begin{array}{l}\text { Plausible bias that raises some doubt } \\
\text { about the results }\end{array}$ & $\begin{array}{l}\text { Unclear risk of bias for } \geq \\
1 \text { key domains }\end{array}$ & $\begin{array}{l}\text { Most information is from studies at low or un- } \\
\text { clear risk of bias }\end{array}$ \\
\hline $\begin{array}{l}\text { High risk of } \\
\text { bias }\end{array}$ & $\begin{array}{l}\text { Plausible bias that seriously weakens } \\
\text { confidence in the results }\end{array}$ & $\begin{array}{l}\text { High risk of bias for } \geq 1 \\
\text { key domains }\end{array}$ & $\begin{array}{l}\text { The proportion of information from studies at } \\
\text { high risk of bias is sufficient to affect the inter- } \\
\text { pretation of results }\end{array}$ \\
\hline
\end{tabular}


Table 2. Effects of intervention: survival/loss rate

\begin{tabular}{|c|c|c|c|c|c|}
\hline Study ID & $\begin{array}{l}\text { Restorative treat- } \\
\text { ment }\end{array}$ & Time points & $\begin{array}{l}\text { Result para- } \\
\text { meters }\end{array}$ & Results & Comment \\
\hline Ma 2012 & $\begin{array}{l}\text { Composite restora- } \\
\text { tions of NCCLs }\end{array}$ & $\begin{array}{l}6 \text { months after the restora- } \\
\text { tion }\end{array}$ & Loss rate & $\begin{array}{l}\text { Lower failure rate in rub- } \\
\text { ber dam group }\end{array}$ & $\begin{array}{l}\text { Chinese } \\
\text { reference, } \\
\text { translated }\end{array}$ \\
\hline $\begin{array}{l}\text { Carvalho } \\
2010\end{array}$ & $\begin{array}{l}\text { Proximal ART restora- } \\
\text { tions in primary molar }\end{array}$ & $\begin{array}{l}6,12,18 \text { and } 24 \text { months after } \\
\text { the restoration }\end{array}$ & $\begin{array}{l}\text { Cumulative } \\
\text { survival rate } \\
\text { of restora- } \\
\text { tions }\end{array}$ & $\begin{array}{l}\text { Both groups had similar } \\
\text { survival rate }\end{array}$ & $\begin{array}{l}\text { Excluded } \\
\text { from analy- } \\
\text { sis due to in- } \\
\text { consistent } \\
\text { data }\end{array}$ \\
\hline $\begin{array}{l}\text { Kemoli } \\
2010\end{array}$ & $\begin{array}{l}\text { Proximal ART restora- } \\
\text { tions in primary mo- } \\
\text { lars }\end{array}$ & $\begin{array}{l}\text { Within } 2 \text { hours, } 1 \text { week, } 1 \\
\text { month, } 5 \text { months, } 1 \text { year, } 1.5 \\
\text { and } 2 \text { years after the restora- } \\
\text { tions }\end{array}$ & $\begin{array}{l}\text { Survival rate } \\
\text { of restora- } \\
\text { tions }\end{array}$ & $\begin{array}{l}\text { Significant higher 2-year } \\
\text { survival rate was observed } \\
\text { in rubber dam group com- } \\
\text { pared to cotton roll isola- } \\
\text { tion group }\end{array}$ & - \\
\hline
\end{tabular}

ART: atraumatic restorative treatment; NCCLs: non-carious cervical lesions.

\section{AP PEN DICES}

\section{Appendix 1. Cochrane Oral Health's Trials Register}

("rubber dam*" or "oral dam*" or "dental dam*" or "latex dam*" or Kofferdam or "Optra dam*" or "Optradam Plus" or Optidam* or Flexidam* or "Hygenic Fiesta")

\section{Appendix 2. Cochrane Central Register of Controlled Trials (CENTRAL) search strategy}

\#1 MeSH descriptor Dental restoration, permanent explode all trees

\#2 MeSH descriptor Dental restoration, temporary explode all trees

\#3 ( (dental in All Text near/5 restor* in All Text) or (teeth in All Text near/5 restor* in All Text) or (tooth in All Text near $/ 5$ restor* in All Text) or (dental in All Text near $/ 5$ fill* in All Text) or (teeth in All Text near $/ 5$ fill* in All Text) or (tooth in All Text near $/ 5$ fill* in All Text) )

\#4 MeSH descriptor Dental atraumatic restorative treatment this term only

\#5 ( (dental in All Text or tooth in All Text or teeth in All Text) and ("atraumatic restorative treatment" in All Text or ART in All Text) )

\#6 MeSH descriptor Dental amalgam this term only

\#7 MeSH descriptor Glass ionomer cements this term only

\#8 ( (dental in All Text or tooth in All Text or teeth in All Text) and (restor* in All Text and (inlay in All Text or in-lay in All Text or onlay in All Text or on-lay in All Text or post* in All Text or dowel ${ }^{\star}$ in All Text or pin* in All Text) ))

\#9 ( (dental in All Text or tooth in All Text or teeth in All Text) and (amalgam* in All Text or resin* in All Text or cement* in All Text or ionomer* in All Text or compomer* in All Text or composite* in All Text) )

\section{\#10 MeSH descriptor Crowns explode all trees}

\#11 ( (dental in All Text near/5 crown* in All Text) or (tooth in All Text near/5 crown* in All Text) or (teeth in All Text near $/ 5 \mathrm{crown}$ * in All Text) or (dental in All Text near $/ 5$ coronal $^{*}$ in All Text) or (tooth in All Text near $/ 5$ coronal ${ }^{*}$ in All Text) or (teeth in All Text near $/ 5$ coronal ${ }^{*}$ in All Text) )

\#12 MeSH descriptor Denture, partial explode all trees

\#13 MeSH descriptor Dental veneers explode all trees

Rubber dam isolation for restorative treatment in dental patients (Review) 
\#14 ( (dental in All Text or tooth in All Text or teeth in All Text) and (bridge* in All Text or veneer ${ }^{\star}$ in All Text or pontic* in All Text or laminate* in All Text) )

\#15 (partial in All Text near/5 denture* in All Text)

$\# 16$ (\#1 or \#2 or \#3 or \#4 or \#5 or \#6 or \#7 or \#8 or \#9 or \#10 or \#11 or \#12 or \#13 or \#14 or \#15)

\#17 MeSH descriptor Rubber dams this term only

\#18 ( (rubber in All Text near/6 dam* in All Text) or (oral in All Text near/6 dam* in All Text) or (dental in All Text near/6 dam* in All Text) or

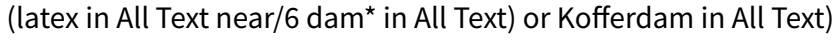

\#19 ("Optra Dam" in All Text or "OptraDam Plus" in All Text or OptiDam in All Text or FlexiDam in All Text or "Hygenic Fiesta" in All Text)

\#20 (\#17 or \#18 or \#19)

\#21 (\#16 and \#20)

\section{Appendix 3. MEDLINE Ovid search strategy}

1. exp Dental restoration, permanent/

2. exp Dental restoration, temporary/

3. ((dental or tooth or teeth) adj5 (restor\$ or fill\$)).ti,ab.

4. Dental atraumatic restorative treatment/

5. ((dental or tooth or teeth) and ("atraumatic restorative treatment" or ART)).ti,ab.

6. Dental amalgam/

7. Glass ionomer cements/

8. ((dental or tooth or teeth) and (restor\$ and (inlay or in-lay or onlay or on-lay or post\$ or dowel\$ or pin\$))).mp.

9. ((dental or tooth or teeth) adj5 (amalgam\$ or resin\$ or cement\$ or ionomer\$ or compomer\$ or composite\$)).mp.

10. exp Crowns/

11. ((dental or tooth or teeth) adj5 (crown\$ or coronal\$)).ti,ab.

12. exp Denture, Partial/

13. exp Dental veneers/

14. ((dental or tooth or teeth) adj5 (bridge\$ or veneer\$ or pontic\$ or laminate\$)).mp.

15. (partial adj5 denture\$).mp.

16. or/1-15

17. Rubber dams/

18. ((rubber adj dam\$) or (oral adj dam\$) or (dental adj dam\$) or (latex adj dam\$) or Kofferdam).mp.

19. ("Optra Dam" or "OptraDam Plus" or OptiDam or FlexiDam or "Hygenic Fiesta").mp.

20. or/17-19

\section{Appendix 4. Embase Ovid search strategy}

1. exp Reparative dentistry/

2. ((dental or tooth or teeth) adj5 (restor\$ or fill\$)).ti,ab.

3. ((dental or tooth or teeth) and ("atraumatic restorative treatment" or ART)).ti,ab.

4. Dental alloy/ 
5. Glass ionomer/

6. ((dental or tooth or teeth) and (restor\$ and (inlay or in-lay or onlay or on-lay or post\$ or dowel\$ or pin\$))).mp.

7. ((dental or tooth or teeth) adj5 (amalgam\$ or resin\$ or cement\$ or ionomer\$ or compomer\$ or composite\$)).mp.

8. exp Crowns/

9. ((dental or tooth or teeth) adj5 (crown\$ or coronal\$)).ti,ab.

10. $\exp$ Denture

11. ((dental or tooth or teeth) adj5 (bridge $\$$ or veneer $\$$ or pontic $\$$ or laminate\$)).mp.

12. (partial adj5 denture\$).mp.

13. or/1-12

14. ((rubber adj dam\$) or (oral adj dam\$) or (dental adj dam\$) or (latex adj dam\$) or Kofferdam).mp.

15. ("Optra Dam" or "OptraDam Plus" or OptiDam or FlexiDam or "Hygenic Fiesta").mp.

16. 14 or 15

17. 13 and 16

\section{Appendix 5. LILACS BIREME Virtual Health Library search strategy}

(dental or dentária or tooth or teeth or dente\$ or diente\$) [Words] and (Mh Rubber dams or "rubber dam\$" or "dique\$ de goma" or "dique\$ de borracha" or "dental dam\$" or "latex dam\$" or "oral dam\$" or Kofferdam or "Optra Dam" or "OptraDam Plus" or OptiDam or FlexiDam or "Hygenic Fiesta") [Words]

\section{Appendix 6. SciELO BIREME Virtual Health Library search strategy}

rubber dam

\section{Appendix 7. CBM search strategy}

1. Mesh: rubber dam

2. Key word: rubber dam

3. \#2 or \#1

This search strategy was translated from Chinese.

\section{Appendix 8. VIP search strategy}

rubber dam

This search strategy was translated from Chinese.

\section{Appendix 9. CNKI search strategy}

rubber dam

This search strategy was translated from Chinese.

Appendix 10. US National Institutes of Health Ongoing Trials Register (ClinicalTrials.gov) and the WHO International Clinical Trials Registry Platform search strategy

rubber dam

\section{Appendix 11. OpenGrey search strategy}

rubber dam

\section{Appendix 12. Sciencepaper search strategy}

rubber dam 
This search strategy was translated from Chinese.

\section{CONTRIBUTIONS OF AUTHORS}

Screening the search results and retrieving the papers: Yan Wang (YW), He Yuan (HY).

Data extraction and risk of bias assessment: YW, HY and Chunjie Li (CL).

Analysing the data and interpreting the results: $\mathrm{CL}, \mathrm{YW}$ and May CM Wong (MW).

Writing the results, discussion, conclusions and abstract: YW, CL, HY and MW.

Providing a clinical perspective: Xuedong Zhou (XZ), Jing Zou (JZ) and Zongdao Shi (ZS).

$\mathrm{YW}, \mathrm{CL}$, and $\mathrm{HY}$ contributed equally to producing this systematic review.

\section{DECLARATIONS OF INTEREST}

Yan Wang: none known.

Chunjie Li: none known.

He Yuan: none known.

May CM Wong: none known. May CM Wong is an editor with Cochrane Oral Health.

Jing Zou: none known.

Zongdao Shi: none known.

Xuedong Zhou: none known.

\section{SOURCES OF SUPPORT}

\section{Internal sources}

- West China School of Stomatology, Sichuan University, China.

- West China Hospital of Stomatology, Sichuan University, China.

- State Key Laboratory of Oral Diseases, Sichuan University, China.

\section{External sources}

- UK Cochrane Centre, UK.

- Cochrane Oral Health, UK.

- Cochrane Oral Health Global Alliance, Other.

The production of Cochrane Oral Health reviews has been supported financially by our Global Alliance since 2011 (ohg.cochrane.org/ partnerships-alliances). Contributors over the last year have been: British Association for the Study of Community Dentistry, UK; British Society of Paediatric Dentistry, UK; Centre for Dental Education and Research at All India Institute of Medical Sciences, India; National Center for Dental Hygiene Research \& Practice, USA; New York University College of Dentistry, USA; NHS Education for Scotland, UK.

- National Institute for Health Research (NIHR), UK.

This project was supported by the NIHR, via Cochrane Infrastructure funding to Cochrane Oral Health. The views and opinions expressed therein are those of the review authors and do not necessarily reflect those of the Systematic Reviews Programme, the NIHR, the NHS or the Department of Health.

\section{DIFFERENCES BETWEEN PROTOCOLAND REVIEW}

Added participant acceptance/satisfaction as a secondary outcome.

Used risk ratio as a measure of the survival/success rate of the restorative treatment.

Specified types of subgroup analyses intended to perform. 